\title{
Pathological hydrogen peroxide triggers the fibrillization of wild-type SOD1 via sulfenic acid modification of Cys-111
}

Wen-Chang Xu', Jin-Zhao Liang ${ }^{2,3}$, Cheng Li' ${ }^{1}$, Zhi-Xin He', Han-Ye Yuan', Ben-Yan Huang ${ }^{4}$, Xiao-Ling Liu', Bo Tang ${ }^{5}$, Dai-Wen Pang ${ }^{5}$, Hai-Ning Du' ${ }^{6}$ Yi Yang $\mathbb{1}^{7}$, Jie Chen ${ }^{1}$, Lei Wang $\mathbb{1}^{2,3}$, Min Zhang ${ }^{4}$ and Yi Liang ${ }^{1}$

\begin{abstract}
Amyotrophic lateral sclerosis (ALS) involves the abnormal posttranslational modifications and fibrillization of copper, zinc superoxide dismutase (SOD1) and TDP-43. However, how SOD1-catalyzed reaction product hydrogen peroxide affects amyloid formation of SOD1 and TDP-43 remains elusory. 90\% of ALS cases are sporadic and the remaining cases are familial ALS. In this paper, we demonstrate that $\mathrm{H}_{2} \mathrm{O}_{2}$ at pathological concentrations triggers the fibrillization of wild-type SOD1 both in vitro and in SH-SY5Y cells. Using an anti-dimedone antibody that detects sulfenic acid modification of proteins, we found that Cys-111 in wild-type SOD1 is oxidized to C-SOH by pathological concentration of $\mathrm{H}_{2} \mathrm{O}_{2}$, followed by the formation of sulfenic acid modified SOD1 oligomers. Furthermore, we show that such SOD1 oligomers propagate in a prion-like manner, and not only drive wild-type SOD1 to form fibrils in the cytoplasm but also induce cytoplasm mislocalization and the subsequent fibrillization of wild-type TDP-43, thereby inducing apoptosis of living cells. Thus, we propose that $\mathrm{H}_{2} \mathrm{O}_{2}$ at pathological concentrations triggers the fibrillization of wildtype SOD1 and subsequently induces SOD1 toxicity and TDP-43 toxicity in neuronal cells via sulfenic acid modification of Cys-111 in SOD1. Our Western blot and ELISA data demonstrate that sulfenic acid modified wild-type SOD1 level in cerebrospinal fluid of 15 sporadic ALS patients is significantly increased compared with 6 age-matched control patients. These findings can explain how $\mathrm{H}_{2} \mathrm{O}_{2}$ at pathologic concentrations regulates the misfolding and toxicity of SOD1 and TDP-43 associated with ALS, and suggest that sulfenic acid modification of wild-type SOD1 should play pivotal roles in the pathogenesis of sporadic ALS.
\end{abstract}

\section{Introduction}

The abnormal post-translational modifications and misfolding of human SOD1 and TDP-43 in motor neuron cells play a crucial role in the etiology of amyotrophic lateral sclerosis (ALS) ${ }^{1-11}$. Ninety percent of ALS cases are sporadic $^{1,3}$; however, little is known about the mechanism underlying most sporadic ALS and the reason why ALS

\footnotetext{
Correspondence: Min Zhang (zhang_min_3464@126.com) or

Yi Liang (liangyi@whu.edu.cn)

${ }^{1}$ State Key Laboratory of Virology, College of Life Sciences, Wuhan University, Wuhan 430072, China

${ }^{2}$ National Laboratory of Biomacromolecules, CAS Center for Excellence in Biomacromolecules, Institute of Biophysics, Chinese Academy of Sciences, Beijing 100101, China

Full list of author information is available at the end of the article

Edited by B. Joseph
}

and frontotemporal lobar degeneration (FTLD) are sometimes overlapping. Pathologically, SOD1 is the major composition of inclusions found in sporadic ALS patient's spinal cord ${ }^{3,12}$, and TDP-43 is the main composition of ubiquitin-positive inclusions observed in ALS and FTLD patients' brain and spinal cord ${ }^{10,11,13}$. The misfolding of SOD1 and TDP-43 has been widely studied during the past 20 years ${ }^{2-7,10,11,14-25}$. The characterization of factors regulating such misfolding is crucial to illuminate the pathology of ALS and FTLD and to help set up medical treatment.

SOD1 is essential for $\mathrm{H}_{2} \mathrm{O}_{2}$ induced oxidative stress during cell signaling ${ }^{26,27}$. Though $\mathrm{H}_{2} \mathrm{O}_{2}$ concentration inside cells is usually very low under physiological 

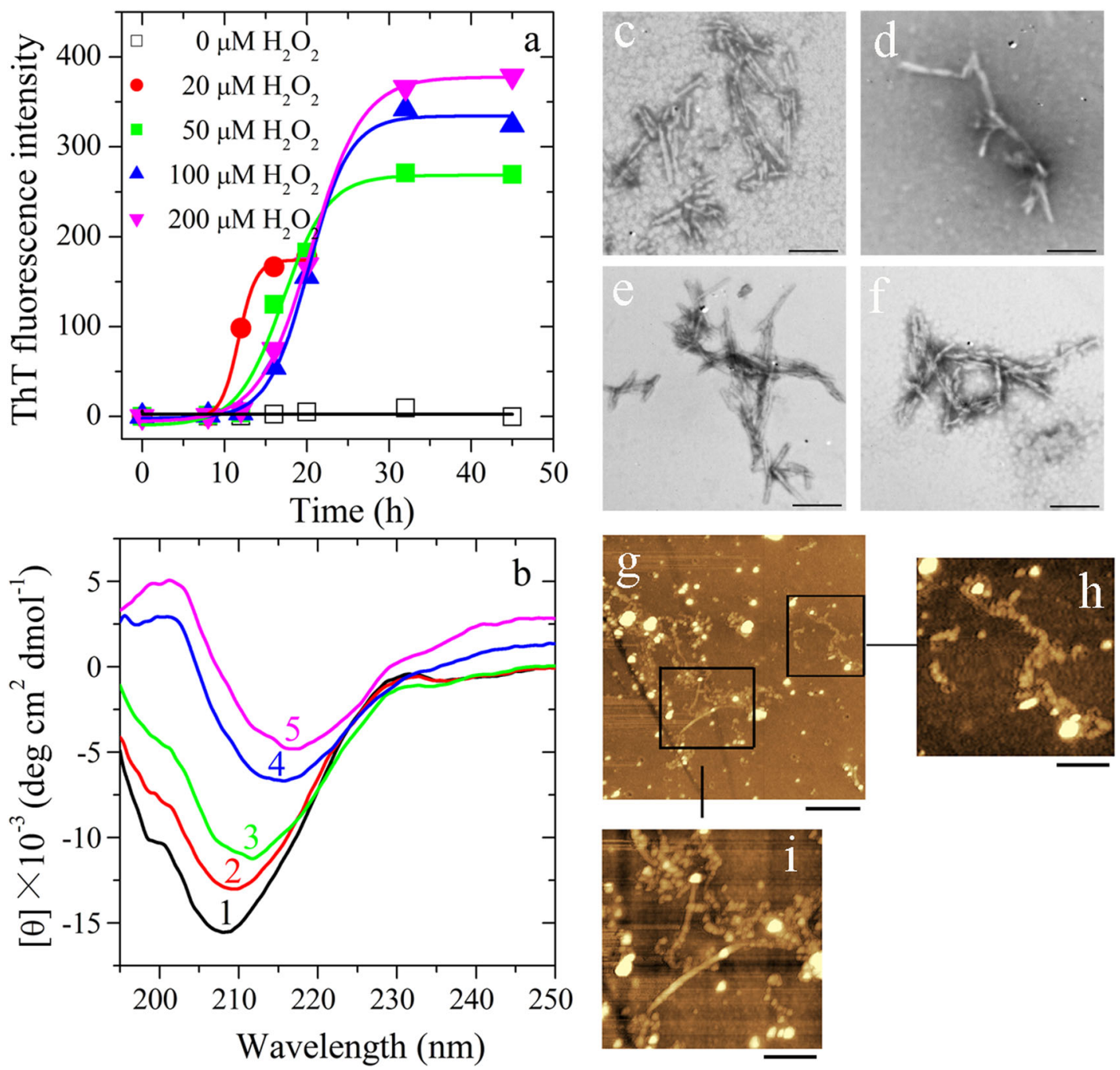

Fig. 1 Hydrogen peroxide at pathological concentrations triggers the fibrillization of wild-type human SOD1 in vitro. Thirty micro mole apo wild-type SOD1 (a) was treated without or with $20-200 \mu \mathrm{M} \mathrm{H}_{2} \mathrm{O}_{2}$ in $20 \mathrm{mM} \mathrm{Tris-HCl}$ buffer ( $\mathrm{pH} 7.4$ ) and at $37^{\circ} \mathrm{C}$ with constant agitation for up to $45 \mathrm{~h}$ and analyzed by ThT binding assays (a), or for $45 \mathrm{~h}$ (curves 1 and 3-5) or $20 \mathrm{~h}$ (curve 2) and analyzed by CD spectroscopy (b). The $\mathrm{H}_{2} \mathrm{O}_{2}$ concentrations were $0 \mu \mathrm{M}$ (open square in (a) or curve 1 in (b)), $20 \mu \mathrm{M}$ (solid circle in (a) or curve 2 in (b)), $50 \mu \mathrm{M}$ (solid square in (a) or curve 3 in (b)), $100 \mu \mathrm{M}$ (solid up triangle in (a) or curve 4 in (b)), and $200 \mu \mathrm{M}$ (solid down triangle in (a) or curve 5 in (b)), respectively. Solid lines show the best sigmoidal fit for the ThT intensity-time curves (a). Negative-stain transmission electron micrographs ( $\mathbf{c}-\mathbf{f})$ and AFM images $(\mathbf{g}$-i) of aggregates produced from $30 \mu \mathrm{M}$ apo wild-type SOD1 incubated with $20-200 \mu \mathrm{M} \mathrm{H} \mathrm{O}_{2}(\mathbf{c}, 20 \mu \mathrm{M} ; \mathbf{d}, 50 \mu \mathrm{M} ; \mathbf{e}, \mathbf{g}-\mathbf{i}, 100 \mu \mathrm{M}$; and f, $200 \mu \mathrm{M})$ at $37^{\circ} \mathrm{C}$ for $45 \mathrm{~h}$ or $20 \mathrm{~h}$ (e). The enlarged regions (h) and (i) show two-fold and four-fold enlarged images from ( $\mathbf{g}$ ), respectively, and display the detailed structure of SOD1 fibrils. The scale bars are $200 \mathrm{~nm}(\mathbf{c}-\mathbf{f}), 2 \mu \mathrm{m}(\mathbf{g}), 1 \mu \mathrm{m}(\mathbf{h})$, and $500 \mathrm{~nm}$ (i), respectively

conditions, it can increase up to $150 \mu \mathrm{M}$ under pathological oxidative conditions ${ }^{26,28-32}$. It has been demonstrated that an iper-oxidized form of wild-type SOD1 with toxic properties exist not only in sporadic ALS patient-derived lymphoblasts, but also in healthy control lymphoblasts treated with $\mathrm{H}_{2} \mathrm{O}_{2}$ at a pathological concentration ${ }^{17}$. However, how $\mathrm{H}_{2} \mathrm{O}_{2}$ at pathological concentrations $(10-100 \mu \mathrm{M})^{17,29}$, a product of SOD1catalyzed reaction ${ }^{9}$, regulates the misfolding and toxicity of wild-type SOD1 and TDP-43 in neuronal cells, associated with sporadic ALS and FTLD, remains elusory.

In this study, we used pathological concentration of $\mathrm{H}_{2} \mathrm{O}_{2}$ to trigger the oligomerization and fibrillization of wild-type human SOD1. Our results indicate that pathological $\mathrm{H}_{2} \mathrm{O}_{2}$ did trigger the fibrillization of wild-type SOD1 via sulfenic acid modification of Cys-111 (C-SOH) in this enzyme in living neuronal cells, accompanied by cytoplasm mislocalization and fibrillization of wild-type human TDP-43, thereby inducing neuronal apoptosis. 


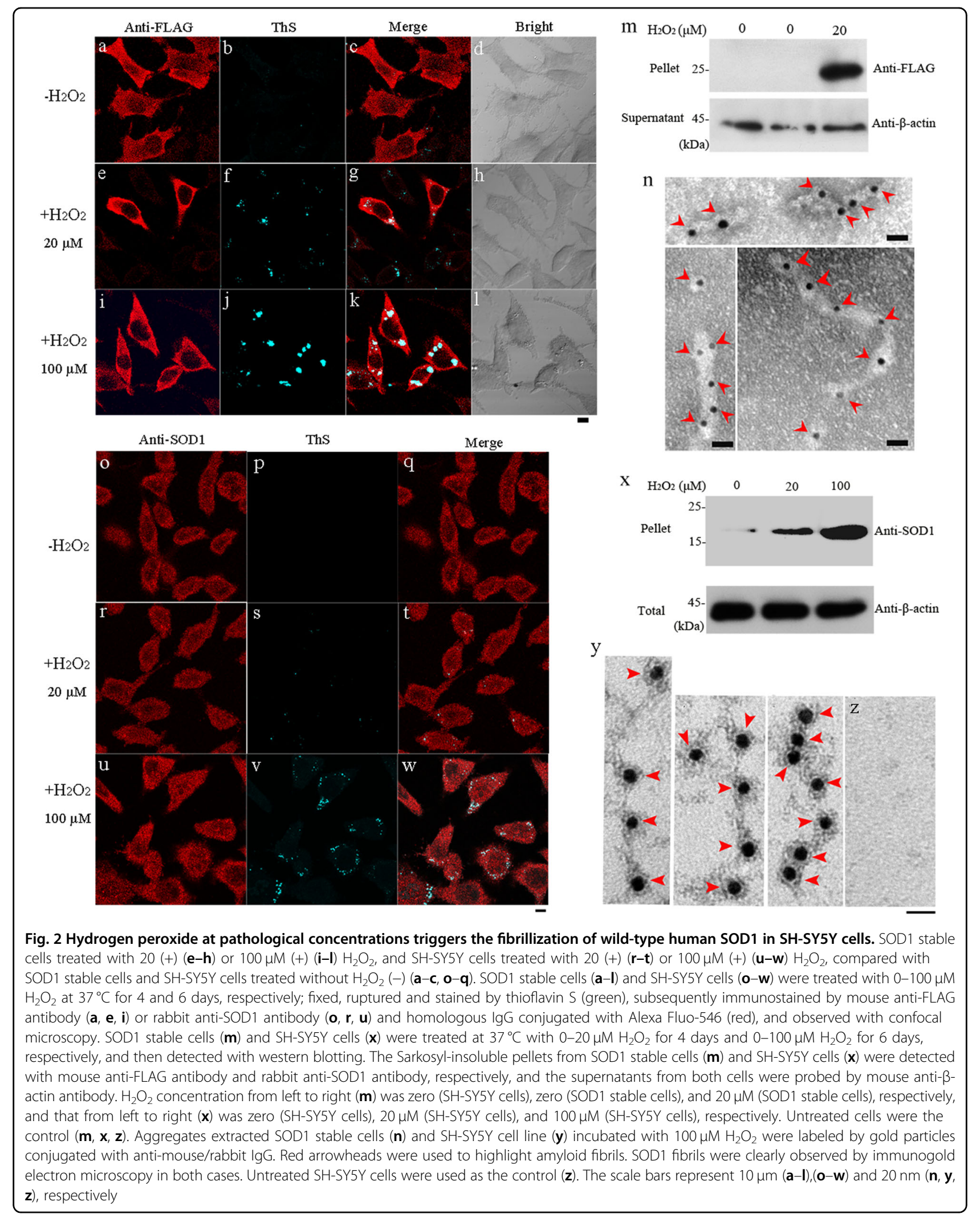


What is more is that we observed a significant increase of sulfenic acid-modified wild-type SOD1 level in cerebrospinal fluid (CSF) of sporadic ALS patients compared with age-matched controls. Our findings link SOD1/TDP43 misfolding and disease-causing functions regulated by pathological $\mathrm{H}_{2} \mathrm{O}_{2}$ to the pathology of sporadic ALS and FTLD.

\section{Results}

\section{Pathological concentration of hydrogen peroxide triggers} SOD1 fibrillization

As shown in Fig. 1a, at pH 7.4, apo wild-type SOD1 (apo-SOD1) did form fibrils when treated with 20, 50, 100, or $200 \mu \mathrm{M} \mathrm{H} \mathrm{H}_{2} \mathrm{O}_{2}$, but did not form fibrils when treated without $\mathrm{H}_{2} \mathrm{O}_{2}$ (Fig. 1a). Interestingly, we found that an increasing concentration of $\mathrm{H}_{2} \mathrm{O}_{2}$ from 20 to $200 \mu \mathrm{M}$ increased the amount of apo-SOD1 filaments by remarkably enhancing the maximum ThT fluorescence intensity, but dramatically decelerated the fibrillization of apo-SOD1 by elongating the lag time to a great extent (from $9.48 \pm 0.60$ to $14.6 \pm 0.8 \mathrm{~h}$ ), indicating a delay in the nucleation phase (Fig. 1a). The fibrillization of apo-SOD1 induced by $20-200 \mu \mathrm{M} \mathrm{H}_{2} \mathrm{O}_{2}$ was further confirmed by $\mathrm{CD}$ spectroscopy, TEM, and $\mathrm{AFM}^{33-35}$. As seen from Fig. $1 \mathrm{~b}$, in the absence of $\mathrm{H}_{2} \mathrm{O}_{2}$, the $\mathrm{CD}$ spectrum measured for apo-SOD1 had a weakly positive band at $230 \mathrm{~nm}$ and a strong negative peak at $208 \mathrm{~nm}$, which reflects the antiparallel $\beta$-strand architecture of apo-SOD ${ }^{36}$. With the increase of $\mathrm{H}_{2} \mathrm{O}_{2}$ concentration from 20 to $200 \mu \mathrm{M}$, the positive peak at $230 \mathrm{~nm}$ of apo-SOD1 disappeared

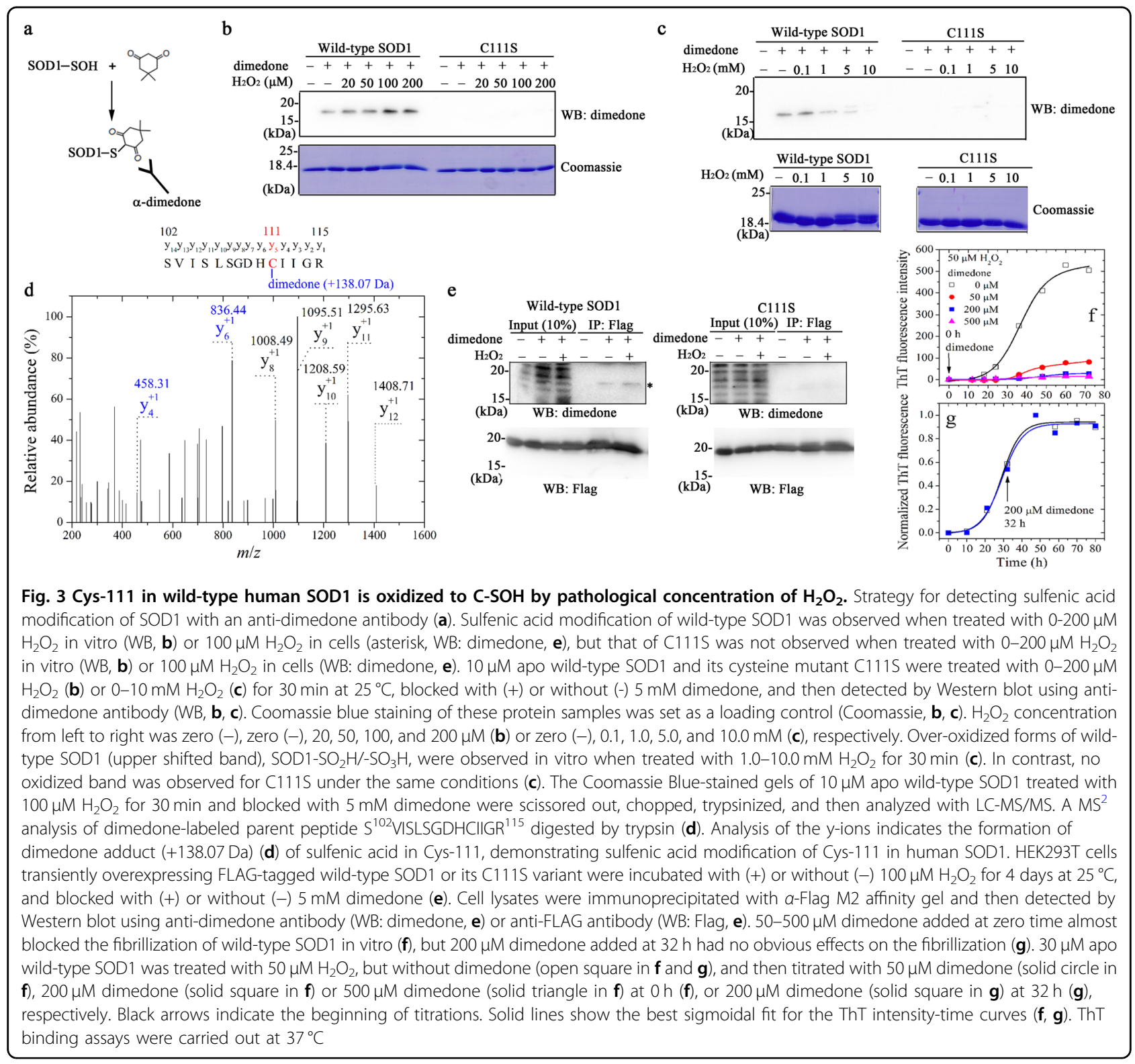




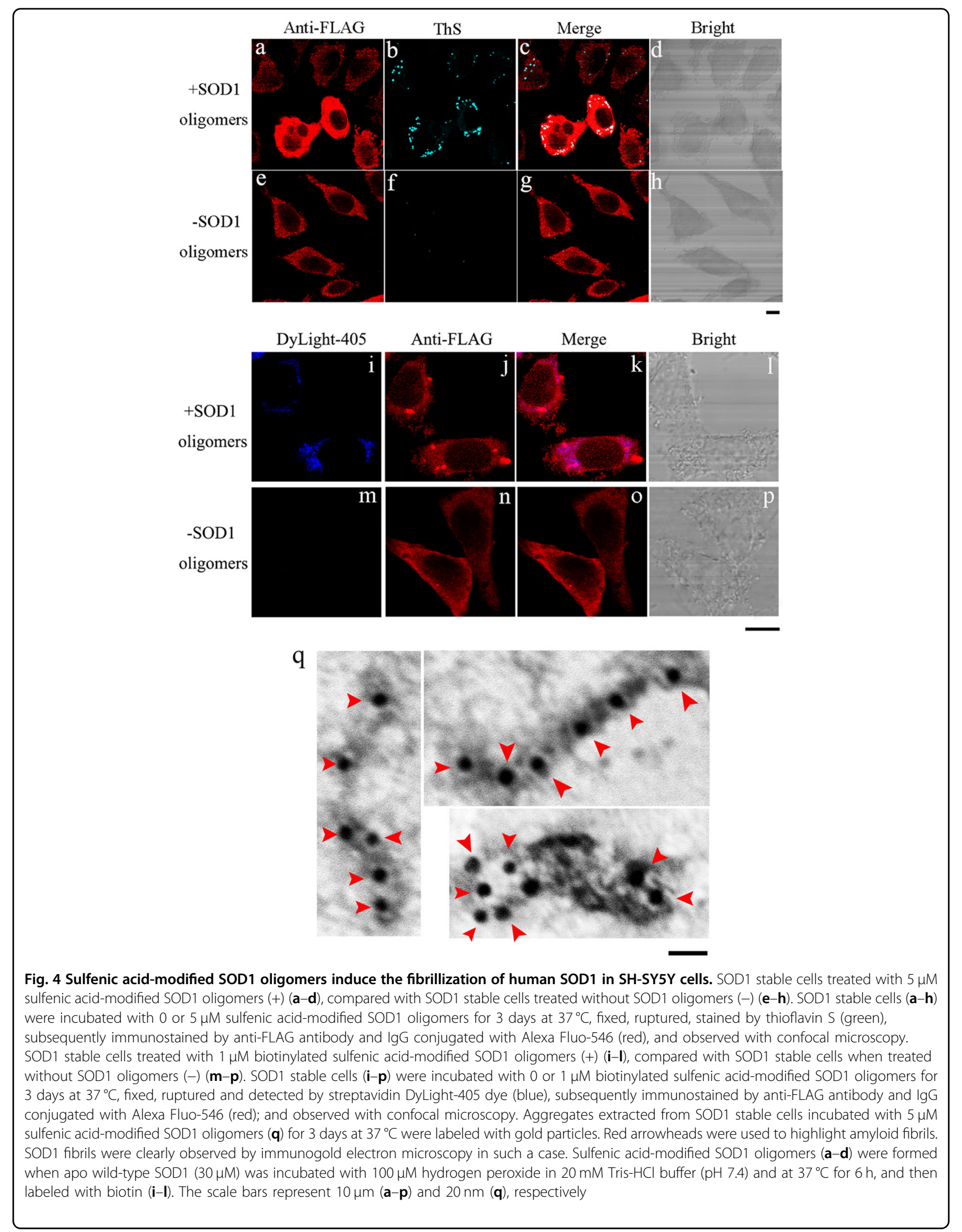


gradually and the negative peak of apo-SOD1 gradually moved into $216 \mathrm{~nm}$ (Fig. 1b), indicating that apo-SOD1 formed amyloid fibrils with $\beta$-sheet-rich conformation under such conditions. TEM images indicate that an increasing concentration of $\mathrm{H}_{2} \mathrm{O}_{2}$ from 20 to $200 \mu \mathrm{M}$ did not have significant effect on the morphology of apoSOD1 aggregates (Fig. 1c-f). The fibrils of apo-SOD1 appear twisted and with a branched structure with a length of $100-300 \mathrm{~nm}$ under all conditions (Fig. 1c-f). However, similar to those previously reported ${ }^{30}, \mathrm{H}_{2} \mathrm{O}_{2}$ at high concentrations induced non-amyloid aggregation of apo-SOD1 (Figure S1a, b). Some long amyloid fibrils (Fig. 1g, i) and some beaded amyloid fibrils (Fig. 1g, h) were also observed using AFM when apo-SOD1 was treated with $100 \mu \mathrm{M} \mathrm{H}_{2} \mathrm{O}_{2}$. Clearly, apo-SOD1 did form fibrils when treated with $20-200 \mu \mathrm{M} \mathrm{H}_{2} \mathrm{O}_{2}$ (Fig. 1a-i), but did not form fibrils when treated without $\mathrm{H}_{2} \mathrm{O}_{2}$ (Fig. 1a, b) or with 1.0-2.0 $\mathrm{mM} \mathrm{H}_{2} \mathrm{O}_{2}$ (Figure S1a,b). Therefore, it is pathological $\mathrm{H}_{2} \mathrm{O}_{2}$ that triggered wild-type SOD1 fibrillization.

We then studied the effect of $\mathrm{H}_{2} \mathrm{O}_{2}$ treatment on wildtype SOD1 fibrillization in SH-SY5Y cells. As shown in Fig. 2, when treated with 20 (Fig. 2e-h, r-t) or $100 \mu \mathrm{M}$ (Fig. 2i-l, u-w) $\mathrm{H}_{2} \mathrm{O}_{2}$, not only wild-type SOD1 formed fibrils in SOD1 stable cells but also endogenous SOD1 formed fibrils in cytoplasm of SH-SY5Y cells. These were detected with anti-FLAG antibody (red) or anti-SOD1 antibody (red) and ThS staining (green) (Fig. 2a, b, e, f, i, j, $\mathrm{o}, \mathrm{p}, \mathrm{r}, \mathrm{s}, \mathrm{u}, \mathrm{v})$. The merge image (white or light gray) proved that stably expressed wild-type SOD1 or endogenous SOD1 was co-localized with ThS-positive amyloids (Fig. 2c, g, k, q, t, w). As seen from Fig. 2, wild-type SOD1 formed amyloid fibrils in SOD1 stable cells when treated with $20 \mu \mathrm{M} \mathrm{H}_{2} \mathrm{O}_{2}(\mathrm{~m})$, and endogenous SOD1 formed fibrils in SH-SY5Y cells when treated with 20 or $100 \mu \mathrm{M} \mathrm{H}_{2} \mathrm{O}_{2}(\mathrm{x})$, as detected by Western blot. Furthermore, an increasing concentration of $\mathrm{H}_{2} \mathrm{O}_{2}$ from 20 (Fig. 2 $\mathrm{f}, \mathrm{g}, \mathrm{s}, \mathrm{t}, \mathrm{x}$ ) to $100 \mu \mathrm{M}$ (Fig. $2 \mathrm{j}, \mathrm{k}, \mathrm{v}, \mathrm{w}, \mathrm{x}$ ) resulted in a remarkable increase in the amount of SOD1 fibrils, as indicated by the growing intensity of white or light gray spots or by the growing densities of SOD1 fibril bands. Gold particles were used to label the aggregates extracted from SOD1 stable cells and SH-SY5Y cell line incubated with $100 \mu \mathrm{M} \mathrm{H} \mathrm{H}_{2} \mathrm{O}_{2}$, and SOD1 fibrils were clearly observed using immunogold electron microscopy ${ }^{37,38}$ in both cases (Fig. 2n, y). Taken together, both stably expressed wild-type SOD1 and endogenous SOD1 formed amyloid fibrils in cytoplasm of SH-SY5Y cells treated with $20 \mu \mathrm{M}$ (Fig. 2e-h, m, r-t) or $100 \mu \mathrm{M}$ (Fig. 2i-l, n, u-w, x, y) $\mathrm{H}_{2} \mathrm{O}_{2}$, but did not form amyloid fibrils when treated without $\mathrm{H}_{2} \mathrm{O}_{2}$ (Fig. 2a-c, o-q, m, x, z). Therefore, pathological $\mathrm{H}_{2} \mathrm{O}_{2}$ did trigger fibril formation of wild-type SOD1 in neuronal cells.

\section{Cys-111 in wild-type SOD1 is oxidized to C-SOH by pathological $\mathrm{H}_{2} \mathrm{O}_{2}$}

$\mathrm{H}_{2} \mathrm{O}_{2}$ at high concentrations ( $\left.\geq 1 \mathrm{mM}\right)$ induces nonamyloid aggregation of apo-SOD ${ }^{30}$ by over-oxidizing Cys111 in this protein to $\mathrm{C}-\mathrm{SO}_{2} \mathrm{H}$ and $\mathrm{C}-\mathrm{SO}_{3} \mathrm{H}^{12,31}$, which was confirmed by Figures $\mathrm{S} 1$ and S2. However, as mentioned above, pathological $\mathrm{H}_{2} \mathrm{O}_{2}$ did trigger the fibrillization of wild-type SOD1. We thus wanted to know whether pathological concentration of $\mathrm{H}_{2} \mathrm{O}_{2}$ could oxidize Cys-111 in wild-type SOD1 differently from high concentrations of $\mathrm{H}_{2} \mathrm{O}_{2}$, thereby inducing fibril formation of this protein.

In this study, we detected sulfenic acid modification of SOD1 by pathological concentration of $\mathrm{H}_{2} \mathrm{O}_{2}$ using an anti-dimedone antibody (Fig. 3a). Sulfenic acid modification to wild-type SOD1 was clearly observed when this enzyme was treated with $0-200 \mu \mathrm{M} \mathrm{H}_{2} \mathrm{O}_{2}$ in vitro for $30 \mathrm{~min}$ (Fig. 3b, the top left) or $0-100 \mu \mathrm{M} \mathrm{H}_{2} \mathrm{O}_{2}$ in cells for $2 \mathrm{~h}$ (Fig. 3e, the top left), but for single cysteine mutant C111S, sulfenic acid modification was not observed when incubated with $0-200 \mu \mathrm{M} \mathrm{H}_{2} \mathrm{O}_{2}$ in vitro (Fig. 3b, the top right) or $0-100 \mu \mathrm{M} \mathrm{H}_{2} \mathrm{O}_{2}$ in cells (Fig. 3e, the top right). To our surprise, an upper shifted band representing SOD1- $\mathrm{SO}_{2} \mathrm{H}$ and SOD1- $\mathrm{SO}_{3} \mathrm{H}$ was not observed for apoSOD1 when treated with $0-200 \mu \mathrm{M} \mathrm{H}_{2} \mathrm{O}_{2}$ for $30 \mathrm{~min}$ (Fig. 3b, the bottom left). Interestingly, we found that an increasing concentration of $\mathrm{H}_{2} \mathrm{O}_{2}$ from 0 to $100 \mu \mathrm{M}$ resulted in an increase in the amount of sulfenic acidmodified wild-type SOD1 by remarkably enhancing the density of the SOD1 band probed by anti-dimedone antibody (Fig. 3b, the top left). Further increasing the concentration of $\mathrm{H}_{2} \mathrm{O}_{2}$ up to $5.0 \mathrm{mM}$, however, strongly decreased the amount of sulfenic acid-modified wild-type SOD1 (Fig. 3b, c, the top left), and sulfenic acid modification was not observed when this enzyme was incubated with $10.0 \mathrm{mM} \mathrm{H}_{2} \mathrm{O}_{2}$ for $30 \mathrm{~min}$ (Fig. 3c, the top left). Analysis of the y-ions in Fig. $3 \mathrm{~d}$ indicated the formation of dimedone adduct $(+138.07 \mathrm{Da})$ of sulfenic acid in Cys-111, demonstrating sulfenation of Cys-111 in apoSOD1 when treated with $100 \mu \mathrm{M} \mathrm{H}_{2} \mathrm{O}_{2}$ for $30 \mathrm{~min}$. Clearly, Cys-111 in wild-type SOD1 was oxidized to C-SOH by pathological concentration of $\mathrm{H}_{2} \mathrm{O}_{2}$. Furthermore, 200/500 $\mu \mathrm{M}$ dimedone added at zero time (Fig. 3f) or $1.0 \mathrm{mM}$ dimedone added at $6 \mathrm{~h}$ (Figure S3) almost blocked the fibrillization of apo-SOD1 triggered by 50 or $100 \mu \mathrm{M} \mathrm{H} \mathrm{H}_{2} \mathrm{O}_{2}$ via blocking sulfenic acid modification to SOD1 in the lag phase, the first stage of protein misfolding $^{39}$. In other words, sulfenic acid-modified SOD1 oligomers were formed in the lag phase. In contrast, 200 $\mu \mathrm{M}$ dimedone added at $32 \mathrm{~h}$ in the growth phase did not have obvious effect on the fibrillization of apo-SOD1 induced by $50 \mu \mathrm{M} \mathrm{H}_{2} \mathrm{O}_{2}$ (Fig. 3g). Therefore, pathological $\mathrm{H}_{2} \mathrm{O}_{2}$ did trigger the fibrillization of wild-type SOD1 via sulfenation of Cys-111. 


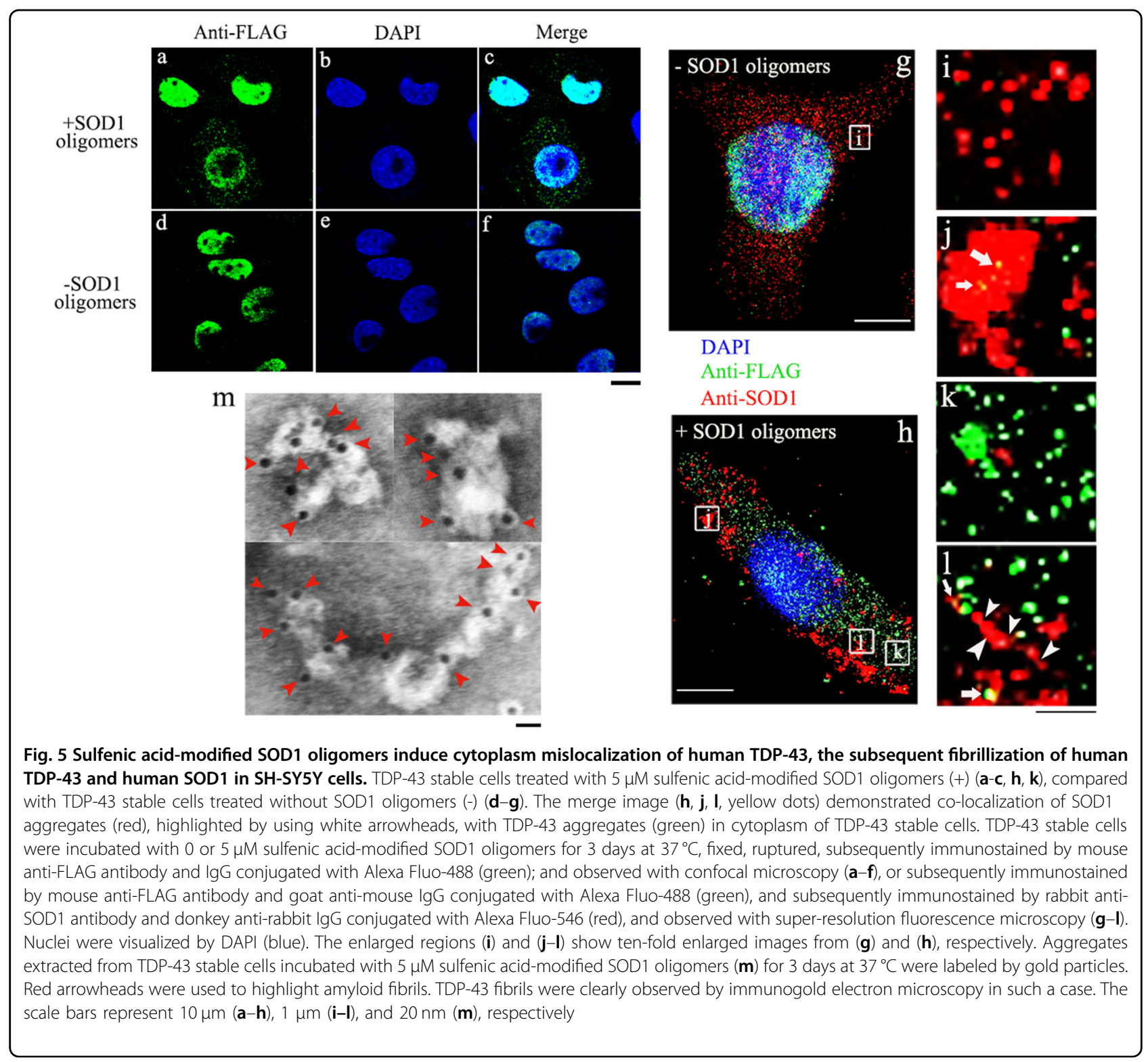

\section{Sulfenic acid-modified SOD1 oligomers induce the fibrillization of wild-type SOD1/TDP-43 in cells}

In this study, we firstly obtained sulfenic acid-modified SOD1 oligomers in the lag phase by incubating $30 \mu \mathrm{M}$ apo-SOD1 with $100 \mu \mathrm{M} \mathrm{H} \mathrm{H}_{2} \mathrm{O}_{2}$ for $6 \mathrm{~h}$. We then studied the effects of such SOD1 oligomers on misfolding of wildtype SOD1 in SH-SY5Y cells. As shown in Fig. 4, when treated with $5 \mu \mathrm{M}$ sulfenic acid-modified SOD1 oligomers (Fig. 4a-d), stably expressed wild-type SOD1 or exogenous SOD1 oligomers entering into SOD1 stable cells formed fibrils in cytoplasm of SOD1 stable cells, as probed by anti-FLAG antibody (red) and ThS staining (green). The merge image (white or light gray) proved that wildtype SOD1 was co-localized with ThS-positive amyloids (Fig. 4c). We further proved that both stably expressed wild-type SOD1 and endogenous SOD1 did form fibrils (red spots) in cytoplasm of SOD1 stable cells treated with $1 \mu \mathrm{M}$ biotinylated sulfenic acid-modified SOD1 oligomers (Fig. 4i-l and S4a-d). As shown in Fig. 4i, k and S4a, c, such SOD1 oligomers, stained by DyLight-405 (blue), entered into SH-SY5Y cells through endocytosis or macropinocytosis ${ }^{15,23,40}$ and were mainly located in the cytoplasm. As shown in Fig. 4i-l and S4a-d, when treated with $1 \mu \mathrm{M}$ biotinylated SOD1 oligomers, not only blue spots but also red spots were observed, demonstrating that both stably expressed wild-type SOD1 and endogenous SOD1 formed fibrils in cytoplasm of SOD1 stable cells, as probed with anti-FLAG antibody (red) or antiSOD1 antibody (red) and streptavidin DyLight-405 dye (blue). As shown in Figure S5, endogenous SOD1 formed 


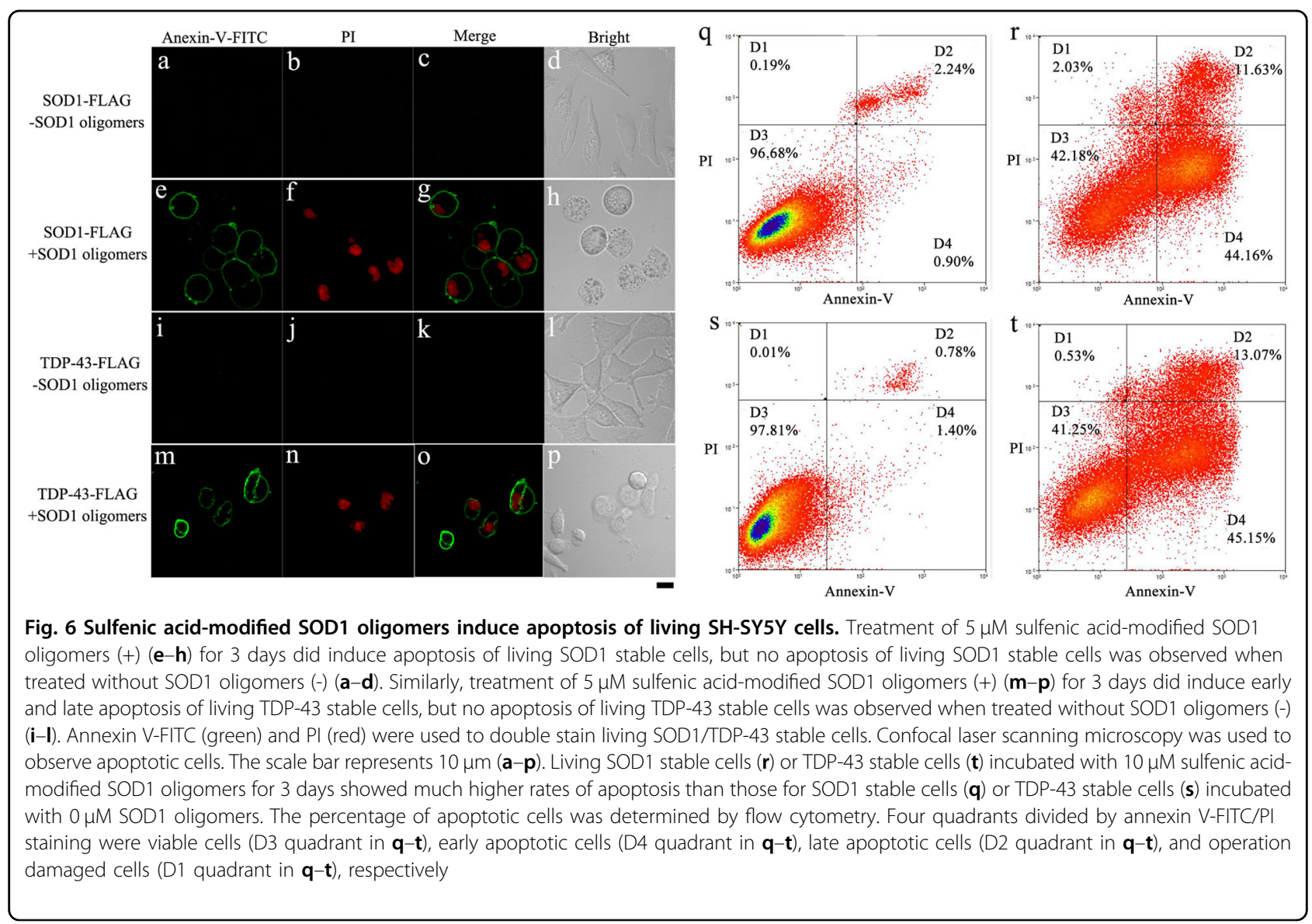

Sarkosyl-insoluble fibrils when SH-SY5Y cells were treated with $5 \mu \mathrm{M}$ sulfenic acid-modified SOD1 oligomers (Fig. 4a-c), as detected by Western blot. However, both stably expressed wild-type SOD1 and endogenous SOD1 did not form amyloid fibrils when cells were not treated with SOD1 oligomers (Fig. 4e-h, m-p, S4e-h, and S5a-c). Gold particles were used to label the aggregates extracted from SOD1 stable cells incubated with $5 \mu \mathrm{M}$ SOD1 oligomers, and SOD1 fibrils were clearly observed in such a case (Fig. 4q). Therefore, sulfenic acid-modified SOD1 oligomers did propagate in a prion-like manner and induce SOD1 fibrillization in neuronal cells.

Thirdly, we studied the effects of sulfenic acid-modified SOD1 oligomers on misfolding of wild-type TDP-43 in SH-SY5Y cells. As shown in Fig. 5, when treated with $5 \mu \mathrm{M}$ sulfenic acid-modified SOD1 oligomers (Fig $5 \mathrm{a}-\mathrm{c}, \mathrm{h}$, k), TDP-43 was partly mislocalized from the nucleus to the cytosol of TDP-43 stable cells. However, stably expressed TDP-43 was correctly localized in the nuclei treated without SOD1 oligomers (Fig. 5d-f, g). Intracellular inclusions consisting of aggregates formed by either stably expressed wild-type TDP-43 (green spots in Fig. 5k) or SOD1 (red spots in Fig. 5j) were observed in TDP-43 stable cells, and the merge image (Fig. 5h, j, l; yellow dots) demonstrated co-localization of SOD1 aggregates (red), highlighted by using white arrowheads, with TDP-43 aggregates in the cytoplasm. Gold particles were used to label the aggregates extracted from TDP-43 stable cells incubated with $5 \mu \mathrm{M}$ SOD1 oligomers, and TDP-43 fibrils were clearly observed in such a case (Fig. $5 \mathrm{~m}$ ). Therefore, sulfenic acid-modified SOD1 oligomers did propagate in a prion-like manner and induce cytoplasm mislocalization and the subsequent fibrillization of TDP-43 in neuronal cells.

\section{Sulfenic acid-modified SOD1 oligomers induce apoptosis of living cells via kindling SOD1/TDP-43 fibrillization}

As mentioned above, both SOD1 and TDP-43 formed amyloid fibrils in cells induced by sulfenic acid-modified SOD1 oligomers, we wonder whether such fibrillization could induce apoptosis of living cells. As seen from Fig. 6e-h, treatment of $5 \mu \mathrm{M}$ sulfenic acid-modified SOD1 oligomers for 3 days not only caused early apoptosis of some living SOD1 stable cells, as marked by FITC (green)conjugated annexin $\mathrm{V}$ binding to phosphatidylserine exposed on the outer cellular membrane, but without propidium iodide $(\mathrm{PI})^{37,38,41,42}$ (red) staining for nuclei, but also induced late apoptosis or necrosis of some other 

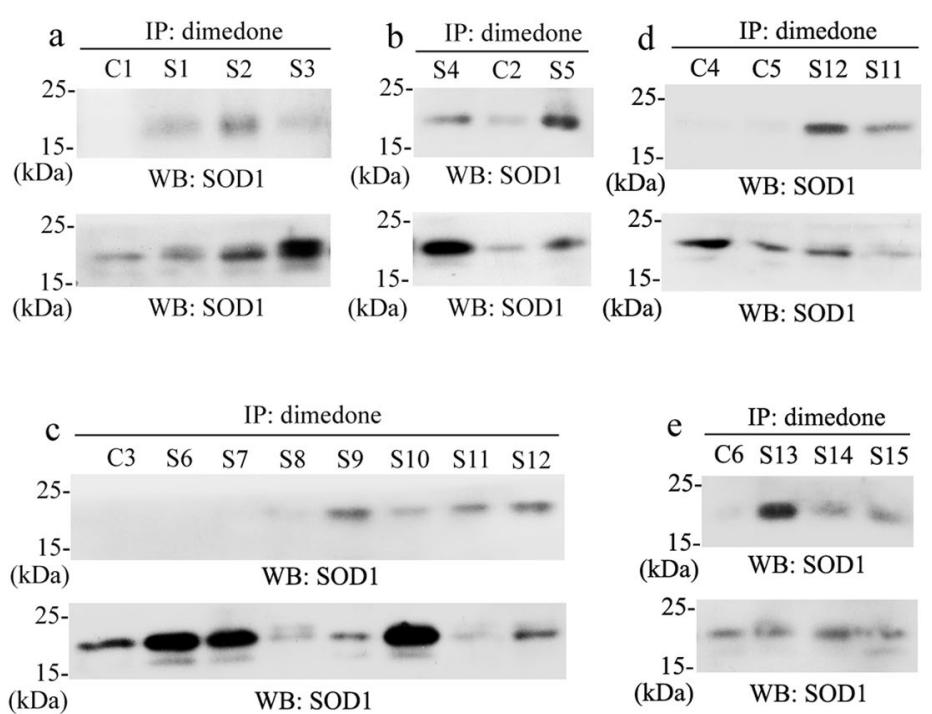
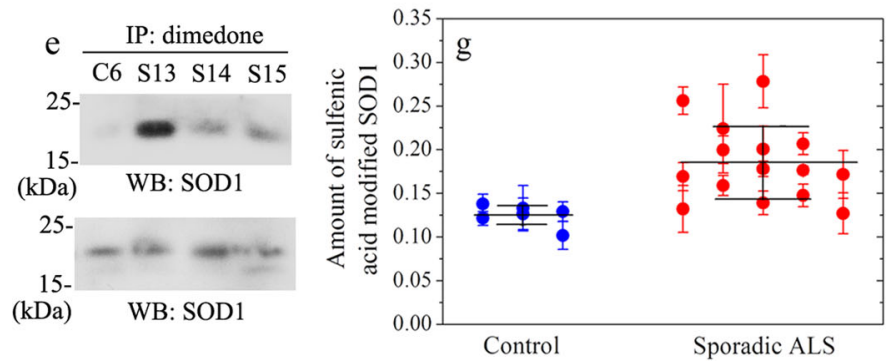

Fig. 7 Sulfenic acid-modified wild-type SOD1 level in cerebrospinal fluid of 15 sporadic ALS patients is significantly increased compared with 6 age-matched control patients (f: Western blot, $F=0.0207$ and $p=0.021 ; g$ : ELISA, $F=0.0126$ and $p=0.0019$ ). Two hundred microlitres of CSF samples were mixed with $2 \mu \mathrm{l}$ of a cocktail protease inhibitors and $2 \mu \mathrm{l}$ of $100 \mathrm{mM}$ dimedone, immunoprecipitated with $1 \mu \mathrm{l}$ of $1.0 \mathrm{mg} / \mathrm{ml}$ rabbit anti-dimedone polyclonal antibody overnight at $4^{\circ} \mathrm{C}$, and then incubated with $20 \mu$ lof Protein $\mathrm{G}$ Agarose beads for $12-14 \mathrm{~h}$ at $4{ }^{\circ} \mathrm{C}$. The beads were washed thrice with PBS buffer, boiled in SDS-PAGE loading buffer without reducing agents for 5 min, and then probed with Western blot using mouse anti-SOD1 antibody (WB: SOD1, the upper lane (a-e)). Another $20 \mu \mathrm{l}$ of CSF samples were boiled in SDS-PAGE loading buffer, probed with Western blot using rabbit anti-SOD1 antibody, and served as the input control (WB: SOD1, the lower lane (a-e)), which represented the total SOD1 content in CSF samples. Sulfenic acid modification of wild-type SOD1 was remarkably observed in CSF samples of 13 patients with sporadic ALS (S1S5 and S8-S15, the upper lane (a-e)), but was not remarkably observed in those of 6 control patients (non-ALS patients) (C1-C6, the upper lane (a-e)) and 2 sporadic ALS patients (S6 and S7, the upper lane, c). Normalized amount of sulfenic acid-modified wild-type SOD1 in CSF samples of 15 patients with sporadic ALS (red solid circle, $\mathbf{f}$ ) and 6 age-matched non-ALS control patients (blue solid circle, $\mathbf{f}$ ) was calculated by the densitometry of sulfenic acid-modified wild-type SOD1 bands (WB: SOD1, the upper lane (a-e)), divided by that of the total SOD1 bands (WB: SOD1, the lower lane $(\mathbf{a}-\mathbf{e})) .100 \mu \mathrm{l}$ of CSF samples were mixed with $1 \mu \mathrm{l}$ of a cocktail of protease inhibitors and $1 \mu \mathrm{l}$ of $100 \mathrm{mM}$ dimedone, and added into each well of the ELISA plates coated with mouse anti-SOD1 antibody. The ELISA plates were incubated with $100 \mu \mathrm{l} / \mathrm{well}$ of $0.5 \mu \mathrm{g} / \mathrm{ml}$ rabbit anti-dimedone antibody followed by $100 \mu \mathrm{l} /$ well of 1/10000 homologous goat anti-rabbit secondary antibody conjugated with horseradish peroxidase. Then $200 \mu \mathrm{l} /$ well of the substrate 3,3',5,5'-tetramethylbenzidine was added and the absorbance of the blue product was measured with a microplate reader at $630 \mathrm{~nm}$. Amount of sulfenic acid-modified wild-type SOD1 in CSF samples of 15 sporadic ALS patients (red solid circle, $\mathbf{g}$ ) and 6 age-matched non-ALS control patients (blue solid circle, $\mathbf{g}$ ) was represented by the absorbance at $630 \mathrm{~nm}$ in each well. Data on absorbance with error bars were expressed as mean \pm S.D. of 3 independent experiments $(\mathbf{g})$. Statistical analyses were done using $t$-test. Values of $p<0.05$ and $p<0.001$ are considered as statistically significant and much significant, respectively

living SOD1 stable cells, as marked by FITC (green)conjugated annexin $\mathrm{V}$ binding to phosphatidylserine exposed on the outer cellular membrane with PI (red) staining for nuclei. Similarly, treatment of $5 \mu \mathrm{M}$ SOD1 oligomers for 3 days induced not only early apoptosis of some living TDP-43 stable cells (green outer membrane without red nucleus), but also late apoptosis or necrosis of some other living SOD1 stable cells (green outer membrane with red nucleus) (Fig. $6 \mathrm{~m}-\mathrm{p}$ ). In contrast, such early and late apoptosis or necrosis was not observed in living cells stably expressing either FLAG-tagged SOD1 (Fig. 6a-d) or FLAG-tagged TDP-43 (Fig. 6i-l) when treated without SOD1 oligomers. As seen from Fig. 6, the percentages of early and late apoptotic cells in living SOD1 stable cells treated with $10 \mu \mathrm{M}$ SOD1 oligomers for 3 days were $44.16 \%$ and $11.63 \%$, respectively (r), much greater than those in SOD1 stable cells not incubated with
SOD1 oligomers (Fig. 6q, $0.90 \%$ and $2.24 \%$, respectively). Similarly, the percentages of early and late apoptotic cells in living TDP-43 stable cells incubated with $10 \mu \mathrm{M}$ SOD1 oligomers for 3 days were $45.15 \%$ and $13.07 \%$, respectively (Fig. 6t), much greater than those in TDP-43 stable cells not incubated with SOD1 oligomers (Fig. 6s, 1.40\% and $0.78 \%$, respectively). Clearly, sulfenic acid-modified SOD1 oligomers did induce apoptosis of living cells via kindling the fibrillization of SOD1 and TDP-43 in cells.

\section{Sulfenic acid-modified wild-type SOD1 level in CSF of sporadic ALS patients is significantly increased}

As mentioned above, we present an interesting observation on $\mathrm{H}_{2} \mathrm{O}_{2}$ dependent aggregation of wild-type SOD1, and identification of sulfenic acid modification of Cys-111 is indeed quite remarkable, we wonder whether this form of post-translational modification could be 
detected in neurons and CSF of ALS patients. We thus determined the amount, by Western blot (Fig. 7a-e) and ELISA (Fig. 7g) methods, of sulfenic acid-modified wild-type SOD1 in CSF from 15 patients with sporadic ALS (ages 42-63, mean \pm SD $50.3 \pm 6.0$ ) and 6 age-matched non-ALS control patients (ages 50-64, mean \pm SD $53.5 \pm 4.8$ ). As shown in Fig. 7a-e, sulfenic acid modification of wild-type SOD1 was remarkably observed in CSF samples from 13 patients with sporadic ALS (S1-S5 and S8-S15), but was not remarkably observed in those of 6 non-ALS control patients (C1-C6) and 2 sporadic ALS patients (S6 and S7). We found that CSF samples from sporadic ALS patients did contain significantly higher levels of sulfenic acid-modified wildtype SOD1 compared to age-matched controls $(0.822 \pm$ 0.629 in sporadic ALS versus $0.220 \pm 0.192$ in controls, $p$ $=0.021$ ) (Fig. 7f). We also observed a significant increase of sulfenic acid-modified wild-type SOD1 level in CSF of sporadic ALS patients, compared to age-matched controls $(0.185 \pm 0.042$ in sporadic ALS versus $0.125 \pm 0.012$ in controls, $p=0.0019$ ) (Fig. 7g). Furthermore, the total SOD1 level in CSF of 15 sporadic ALS patients was not significantly increased compared with 6 age-matched controls $(1.80 \pm 1.36$ in sporadic ALS versus $0.923 \pm 0.455$ in controls, $p=0.079$ ) (Figure S6).

Taken together, our data demonstrated that sulfenic acid-modified wild-type SOD1 level in CSF of 15 patients with sporadic ALS was significantly increased compared to 6 age-matched control patients, suggesting a role of sulfenic acid-modified wild-type SOD1 as a diagnostic biomarker in sporadic ALS.

\section{Discussion}

In this paper, we want to answer the question whether and how $\mathrm{H}_{2} \mathrm{O}_{2}$ at pathological concentrations regulates the fibrillization and cytotoxicity of SOD1 and TDP-43 for two reasons. Firstly, pathological concentrations of $\mathrm{H}_{2} \mathrm{O}_{2}$ could cause oxidative modifications to cellular proteins including SOD $1^{17,29,43,44}$. Secondly, the antioxidant function of SOD $1^{43}$ exposes SOD1 to serious oxidative stress resulting from the accumulation of neurotoxic ROS during aging, and oxidative modifications to SOD1 is further enhanced by long half-life of SOD1 in motor neurons ${ }^{43,45-}$ 47. In this study, we proved that $\mathrm{H}_{2} \mathrm{O}_{2}$ at pathological concentrations did trigger wild-type SOD1 fibrillization via sulfenic acid modification of SOD1. We also demonstrated that the sulfenic acid-modified SOD1 oligomers caused TDP-43 redistribution from the nuclei to the cytoplasm, an ongoing event during ALS progression ${ }^{48}$, and induced SOD1/TDP-43 to form amyloid fibrils in cytoplasm of neuronal cells. In other words, fibrils composed of SOD1 coexisted with those composed of TDP-43 in cells. Interestingly, the accumulation of pathological TDP-43 has been found to coexist with misfolded SOD1 in patient motor neurons ${ }^{7,19}$. Our data establish a novel role for pathological $\mathrm{H}_{2} \mathrm{O}_{2}$, whose concentration increases with age ${ }^{43,47}$, in regulating the misfolding and toxicity of SOD1 and TDP-43.

The Valentine lab has pioneered a study of SOD1 fibril formation under physiological reducing conditions ${ }^{3,22}$, and the Eisenberg lab has reported a structure for toxic SOD1 oligomers ${ }^{49}$. Here, we firstly reported a study of SOD1 fibril formation under pathological oxidative conditions, which are closer to the pathological environments in ALS and FTLD patient's brain and spinal cord $^{11}$. By using anti-dimedone antibody, we found that Cys-111 in wild-type SOD1 was oxidized to $\mathrm{C}-\mathrm{SOH}$ by pathological $\mathrm{H}_{2} \mathrm{O}_{2}$, and demonstrated that a small amount of sulfenic acid-modified SOD1 oligomers did induce the fibrillization and toxicity of SOD1 and TDP-43 in neuronal cells. By using AFM, we observed a mixture of some long amyloid fibrils and abundant spherical or ellipsoidal particles formed by apo-SOD1 when treated with pathological $\mathrm{H}_{2} \mathrm{O}_{2}$. Interestingly, inclusions observed in ALS mouse models and patients are composed of some thick fibrils and spherical or ellipsoidal particles ${ }^{45}$. We thus suggest that post-translational modifications to wild-type SOD1 should play significant roles in the misfolding and cytotoxicity of SOD1 and TDP-43, based on this work and the reported results ${ }^{12,17,50}$. In this study, CSF from ALS patients was chosen for investigation because of the following reasons. Firstly, CSF is a proximal fluid to the site of ALS onset, giving CSF advantages for diagnostic biomarker discovery over more distal fluids including plasma $^{51}$. Secondly, obtaining CSF samples via lumbar puncture is much safer and more practical than biopsy of the brain or spinal cord from ALS patients ${ }^{52}$. Thirdly, obtaining autopsy brain samples from ALS patients is quite difficult in China. ALS and FTLD patients have a significant increase of TDP-43 level in their CSF compared to age-matched controls ${ }^{53,54}$. It has been reported that total SOD1 and misfolded SOD1 in CSF cannot be used as biomarkers for sporadic ALS ${ }^{52,55}$, and it is controversial whether misfolded SOD1 is accumulated in spinal cords and lymphocytes from sporadic ALS patients ${ }^{3,12,17,23,56}$. Therefore, specific SOD1 posttranslational modifications may be an important biomarker for sporadic ALS. In the current study, we reported for the first time that CSF sulfenic acid-modified wild-type SOD1 level was significantly increased in 15 patients with sporadic ALS as compared with 6 agematched control patients, but these ALS patients did not have significantly greater levels of total SOD1 in their CSF than age-matched controls. Moreover, the level of sulfenic acid-modified wild-type SOD1 in CSF could be determined in living ALS patients. A few biomarkers for ALS, such as phosphorylated neurofilament heavy chain and TDP-43 in CSF, have been reported ${ }^{52-54,57-59}$. Our 


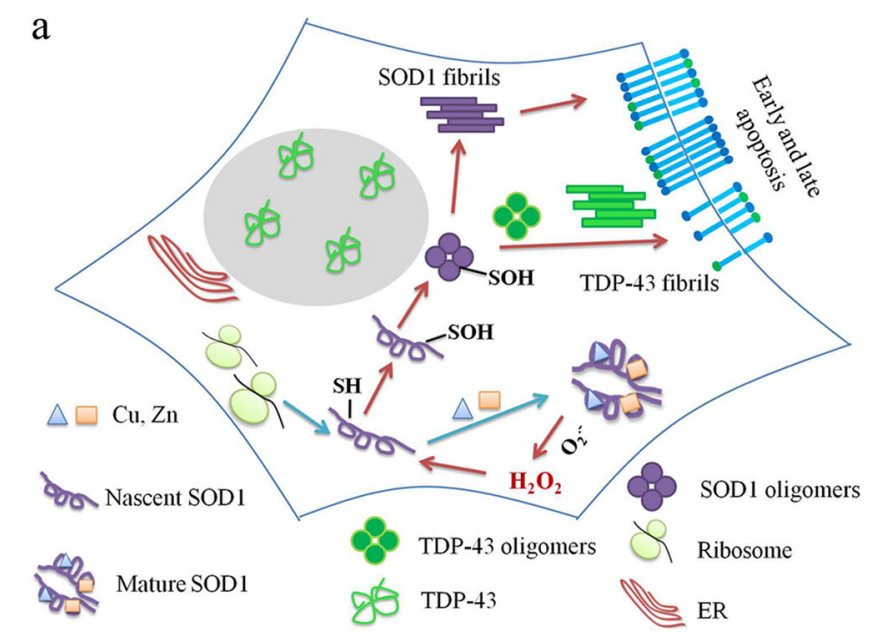

b

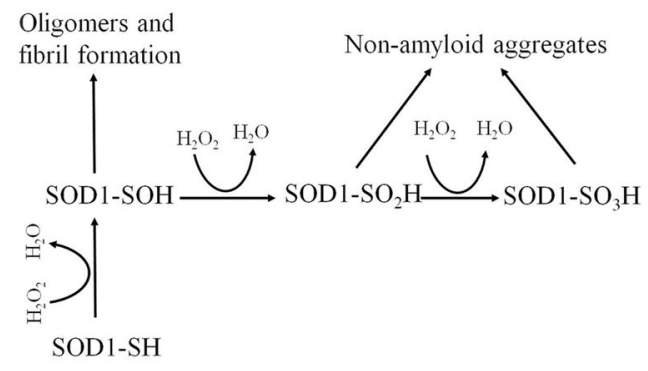

Fig. 8 A hypothetical model shows how pathologic concentration of hydrogen peroxide triggers the misfolding of SOD1 via sulfenic acid modification of Cys-111, and thus induces SOD1 toxicity and TDP-43 toxicity in neuronal cells. Nascent SOD1 (purple unfolded monomer, apo-SOD1) overexpressed in SH-SY5Y cells emerges from the ribosome (light green), copper (blue triangle), and zinc (orange square) bind to the correct binding sites, and the disulfide bond and mature SOD1 (purple dimer) are formed step by step (a). Mature SOD1 catalyzes the dismutation of superoxide anion $\left(\mathrm{O}_{2}^{\bullet-}\right.$ ) to $\mathrm{H}_{2} \mathrm{O}_{2}$ and $\mathrm{O}_{2}$, and pathological concentration of the product $\mathrm{H}_{2} \mathrm{O}_{2}$ (red) abnormally accumulated in cytoplasm of $\mathrm{SH}-\mathrm{SY} 5 \mathrm{Y}$ cells could then trigger the oligomerization and fibrillization of nascent SOD1 via sulfenic acid modification of Cys-111 (from SOD1-SH to SOD1-SOH, purple), forming sulfenic acid-modified SOD1 oligomers (purple balls) and amyloid fibrils (purple bars) in SH-SY5Y cells (a). Sulfenic acid-modified SOD1 oligomers could induce cytoplasm mislocalization of human TDP-43 (green) (from the nucleus to the cytosol), forming cytoplasmic TDP-43 oligomers (green balls) and cytoplasmic fibrils (green bars), and induce apoptosis of living SH-SY5Y cells, thereby increasing the cytotoxicity of SOD1 and TDP-43 (a). Phosphatidylserine (a) is indicated by blue sticks with green balls. Scheme describing the competition between the major pathway, in which pathological concentration of $\mathrm{H}_{2} \mathrm{O}_{2}$ oxidizes human SOD1 to SOD1-SOH and drives human SOD1 to form highly toxic oligomers and fibrils, and another pathway, in which $\mathrm{H}_{2} \mathrm{O}_{2}$ at high concentrations over-oxidizes human SOD1 to SOD1- $\mathrm{SO}_{2} \mathrm{H}$ and SOD1-SO $\mathrm{S}_{3} \mathrm{H}$ and drives human SOD1 to form non-amyloid aggregates (b)

findings suggest that the quantification of sulfenic acidmodified SOD1 in CSF could have potential value as a diagnostic laboratory tool for sporadic ALS patients, and suggest a role of sulfenic acid-modified wild-type SOD1 as a diagnostic biomarker in sporadic ALS.

Wild-type human SOD1 has four cysteine residues, two of which (Cys-111 and Cys-6) are present as free cysteines $^{31,60,61}$. Cys-111, the most solvent-exposed Cys in human SOD1, is a highly reactive Cys placed on the surface, whereas Cys-6 is deeply buried inside this enzyme $^{31,60,61}$. It has been reported that Cys-111 is a key residue for the aggregation and cytotoxicity of human SOD1 pathogenic mutants ${ }^{62-66}$. The major finding of our study is that $\mathrm{H}_{2} \mathrm{O}_{2}$ at pathological concentrations (as low as $20 \mu \mathrm{M}$ ) did trigger the fibrillization of wild-type human SOD1 via sulfenic acid modification of Cys-111 and subsequently induced SOD1/TDP-43 toxicity in neuronal cells. Therefore, Cys-111 is a key residue for the misfolding and cytotoxicity of wild-type SOD1 kindled by pathological $\mathrm{H}_{2} \mathrm{O}_{2}$, and the sulfenation of Cys-111 in SOD1 could perform a pivotal function in the pathogenesis of sporadic ALS and FTLD.

Figure 8 shows a hypothetical model on how $\mathrm{H}_{2} \mathrm{O}_{2}$ triggers SOD1 fibrillization via sulfenic acid modification of Cys-111. Mature SOD1 catalyzes the disproportionation of $\mathrm{O}_{2}^{--}$to $\mathrm{H}_{2} \mathrm{O}_{2}$ and $\mathrm{O}_{2}$, and pathological $\mathrm{H}_{2} \mathrm{O}_{2}$ abnormally accumulated in the cytoplasm could then trigger nascent SOD1 aggregation via sulfenation of Cys111, forming sulfenic acid-modified SOD1 oligomers and fibrils in neuronal cells. Sulfenic acid-modified SOD1 oligomers could induce TDP-43 cytoplasm localization (mistakenly from the nuclei to the cytoplasm), forming cytoplasmic TDP-43 oligomers and fibrils, and induce early and late apoptosis of neuronal cells, thereby increasing the cytotoxicity of SOD1 and TDP-43. The above model can explain how $\mathrm{H}_{2} \mathrm{O}_{2}$ at pathological concentrations regulates the misfolding and toxicity of SOD1 and TDP-43 in the ALS brain and spinal cord. The inhibition of wild-type SOD1 aggregation by dimedone (this work) and the inhibition of mutant SOD1 aggregation by macrophage migration inhibitory factor ${ }^{67}$ provide a feasible method for treatment of sporadic ALS and familial ALS, respectively.

\section{Materials and Methods}

\section{Materials}

Three dyes, ThT, ThS, and DAPI, and four antibodies, mouse anti-FLAG monoclonal antibody, rabbit anti- 
FLAG monoclonal antibody, $10 \mathrm{~nm}$ gold-labeled antimouse antibody, and mouse anti- $\beta$-tubulin antibody, were bought from Sigma-Aldrich (St. Louis, MO). Sarkosyl and Triton X-100 were purchased from Amresco (Solon, OH). Rabbit anti-SOD1 polyclonal antibody, mouse anti-SOD1 monoclonal antibody, and $10 \mathrm{~nm}$ gold-labeled anti-rabbit antibody were from Abcam (Cambridge, MA). Streptavidin, DyLight-405 conjugated secondary antibody and secondary antibody conjugated with Alexa 546/488 were from Invitrogen (Carlsbad, CA). Anti-dimedone polyclonal antibody was purchased from Millipore (Billerica, MA). Other chemicals were analytical grade, made in China.

\section{SOD1 expression and purification}

Single cysteine mutant C111S was generated by using primers TCTCAGGAGACCATAGCATCATTGGCC/ GGCCAATGATGCTATGGTCTCCTGAGA. The expression, purification, demetalization, and concentration determination of wild-type SOD1 and C111S were the same as described previously,68. AAnalyst-800 atomic absorption spectrometer (PerkinElmer) was used to quantify metal content of SOD1 samples. Samples of wildtype SOD1 and C111S contained less than 5\% of residual metal ions, indicating that the samples were indeed in the apo state.

\section{Cell culture}

SH-SY5Y/HEK293T cells were cultured and HEK293T cells were transiently transfected with FLAGtagged wild-type SOD1 or its C111S variant in pCMVTag 2B vector as described ${ }^{37,38}$. SOD1 stable cells and TDP-43 stable cells were constructed and cultured according to previously published protocols ${ }^{37,38}$. All the below experiments were repeated 3 times.

\section{ThT binding assays}

A $2.5 \mathrm{mM}$ ThT fresh solution was prepared in $20 \mathrm{mM}$ Tris- $\mathrm{HCl}$ buffer at $\mathrm{pH} 7.4$ as described ${ }^{33}$. Thirty micrometer apo wild-type SOD1 was incubated without or with 20-200 $\mu \mathrm{M} \mathrm{H}_{2} \mathrm{O}_{2}$ for up to $45 \mathrm{~h}$. Thirty micrometer apo-SOD1 was incubated with $50 \mu \mathrm{M} \mathrm{H}_{2} \mathrm{O}_{2}$, but without dimedone and then titrated with $50-500 \mu \mathrm{M}$ dimedone at $0 \mathrm{~h}$ or $200 \mu \mathrm{M}$ dimedone at $32 \mathrm{~h}$, respectively, or incubated with $100 \mu \mathrm{M} \mathrm{H}_{2} \mathrm{O}_{2}$, but without dimedone and then titrated with $1.0 \mathrm{mM}$ dimedone. Fifty microlitre of SOD1 samples and $5.0 \mu \mathrm{l}$ of ThT solution were diluted into $20 \mathrm{mM}$ Tris- $\mathrm{HCl}$ buffer, giving an ultimate volume of $0.50 \mathrm{ml}$ and final concentrations of 3 and $25 \mu \mathrm{M}$ for apo wild-type SOD1 and ThT, respectively. LS-55 luminescence spectrometer (Perkin-Elmer) was used to measure ThT fluorescence excited at $440 \mathrm{~nm}$ and emitted at 480 $\mathrm{nm}$ with slit widths of 10.0 and $5.0 \mathrm{~nm}$, respectively. Kinetic experiments were repeated 3 times at $37^{\circ} \mathrm{C}$ with agitation. The determination of kinetic parameters of SOD1 fibrillization was made according to a sigmoidal equation $^{3,33,34}$.

\section{Circular dichroism spectroscopy}

Under standard conditions, $30 \mu \mathrm{M}$ apo wild-type SOD1 was incubated without or with $20-200 \mu \mathrm{M} \mathrm{H}_{2} \mathrm{O}_{2}$ in 20 $\mathrm{mM}$ Tris- $\mathrm{HCl}$ buffer at $\mathrm{pH} 7.4$ and $37^{\circ} \mathrm{C}$ for $45 \mathrm{~h}$ or $20 \mathrm{~h}$. Jasco J-810 spectropolarimeter (Jasco Corp., Tokyo, Japan) was used to obtain far-UV CD spectra of the fibrillization $10 \mu \mathrm{M}$ SOD1. The mean residue molecular weight for SOD1 is 104.6 Da. The mean residue molar ellipticity $(\theta)$ was determined by the equation described ${ }^{69}$.

\section{TEM}

Formation of fibrils by apo wild-type SOD1 incubated with $20-200 \mu \mathrm{M} \mathrm{H}_{2} \mathrm{O}_{2}$ or non-amyloid aggregates by this protein incubated with $1.0-2.0 \mathrm{mM} \mathrm{H}_{2} \mathrm{O}_{2}$ was confirmed by electron microscopy of negatively stained samples. Sample preparation and TEM analysis were described in detail previously ${ }^{33}$.

\section{AFM}

AFM was used to probe the structural order in the aggregates produced from $30 \mu \mathrm{M}$ apo wild-type SOD1 incubated with $100 \mu \mathrm{M} \mathrm{H}_{2} \mathrm{O}_{2}$ with the aim to see if these are still fibrils or disordered complexes. Sample preparation and AFM analysis were described in detail previously $^{33}$.

\section{Laser scanning confocal analysis}

To confirm fibril formation of wild-type SOD1 in cells triggered by pathological concentration of $\mathrm{H}_{2} \mathrm{O}_{2}$ or induced by sulfenic acid-modified SOD1 oligomers, SOD1 stable cells and SH-SY5Y cells were cultured in medium containing $0-100 \mu \mathrm{M} \mathrm{H}_{2} \mathrm{O}_{2}$ for 4 and 6 days, respectively, or grown in medium incubated with $0-5 \mu \mathrm{M}$ sulfenic acid-modified SOD1 oligomers or $0-1 \mu \mathrm{M}$ biotinylated sulfenic acidmodified SOD1 oligomers for 3 days, then fixed and ruptured. The cells were stained with ThS or streptavidin DyLight-405 dye, and coimmunostained with mouse antiFLAG antibody or rabbit anti-SOD1 antibody and homologous secondary antibody conjugated with Alexa Fluo-546.

To observe cytoplasm mislocalization and the subsequent fibrillization of wild-type TDP-43 in cells induced by sulfenic acid-modified SOD1 oligomers, TDP-43 stable cells were grown in medium incubated with $0-5 \mu \mathrm{M}$ sulfenic acid-modified SOD1 oligomers for 3 days, then fixed and ruptured. The cells were coimmunostained with mouse primary anti-FLAG antibody and homologous secondary antibody conjugated with Alexa Fluo-488. The nuclei were stained with DAPI.

Sample preparation and laser scanning confocal analysis were described in detail previously ${ }^{38}$. 


\section{Super-resolution fluorescence microscopy}

To clearly observe cytoplasm mislocalization and the subsequent fibrillization of wild-type TDP-43 in cells induced by sulfenic acid-modified SOD1 oligomers, TDP43 stable cells were grown in medium incubated with 0-5 $\mu \mathrm{M}$ sulfenic acid-modified SOD1 oligomers for 3 days, then fixed and ruptured. The cells were immunostained with primary mouse anti-FLAG antibody and homologous secondary antibody conjugated with Alexa Fluo-488, and then immunostained with primary rabbit anti-SOD1 antibody and secondary donkey anti-rabbit IgG conjugated with Alexa Fluo-546. The nuclei were stained with DAPI. Sample preparation and super-resolution fluorescence analysis were described in detail previously ${ }^{38}$.

\section{Western blot}

SH-SY5Y cells and SOD1 stable cells were grown in medium incubated with $0-100 \mu \mathrm{M} \mathrm{H}_{2} \mathrm{O}_{2}$ for 6 and 4 days, respectively, or grown in medium incubated with $0-5 \mu \mathrm{M}$ sulfenic acid-modified SOD1 oligomers for 3 days, then harvested, lysed, and centrifuged. The supernatants were incubated with Sarkosyl, and the Sarkosyl-insoluble proteins were acquired by ultracentrifugation. Such samples were subjected to SDS-PAGE and transferred onto the membranes, and blocked with $5 \%$ fat-free milk in $100 \mathrm{mM}$ Tris- $\mathrm{HCl}$ buffer containing $150 \mathrm{mM} \mathrm{NaCl}$ and $0.1 \%$ Tween 20. The membranes were incubated with mouse anti-FLAG antibody, 1/2000 rabbit anti-SOD1 antibody or mouse anti- $\beta$-actin antibody, and then $1 / 4000$ secondary antibody conjugated with horseradish peroxidase. The protocol for Western blot was described in detail previously $^{38}$.

\section{Immunoelectron microscopy}

SOD1 stable cells and SH-SY5Y cells were cultured in medium containing $0-100 \mu \mathrm{M} \mathrm{H}_{2} \mathrm{O}_{2}$ for 4 and 6 days, respectively, and SOD1/TDP-43 stable cells were cultured in medium containing $0-5 \mu \mathrm{M}$ sulfenic acid-modified SOD1 oligomers for 3 days. The cells were homogenized and centrifuged at $17,000 \mathrm{~g}$ for $20 \mathrm{~min}$. After centrifugation of the supernatants at $150,000 \mathrm{~g}$ for $30 \mathrm{~min}$, the Sarkosylinsoluble pellets were resuspended in PBS buffer. Sample aliquots of $10 \mu \mathrm{l}$ were absorbed onto nickel grids and incubated with $1 / 300$ mouse anti-FLAG antibody or rabbit anti-SOD1 antibody. After blocked with BSA, 10-nm goldlabeled homologous secondary antibodies were used to incubate the grids. The protocol for immunoelectron microscopy was described in detail previously ${ }^{37,38}$.

\section{Sulfenic acid modification of wild-type SOD1 in vitro}

Ten micrometer of apo wild-type SOD1 and its cysteine mutant C111S were incubated with $0-200 \mu \mathrm{M} \mathrm{H}_{2} \mathrm{O}_{2}$ or 0-10 $\mathrm{mM} \mathrm{H}_{2} \mathrm{O}_{2}$ for $30 \mathrm{~min}$ at $25^{\circ} \mathrm{C}$, and blocked with $5 \mathrm{mM}$ dimedone. The proteins were subjected to $13.5 \%$
SDS-PAGE and transferred onto the membranes (Millipore), and blocked with $5 \%$ fat-free milk in $50 \mathrm{mM}$ Tris$\mathrm{HCl}$ buffer containing $150 \mathrm{mM} \mathrm{NaCl}$ and $0.05 \%$ Tween 20 . The membranes were incubated with $1 / 1000$ antiFLAG antibody or 1/1000 anti-dimedone antibody, and then $1 / 5000$ secondary antibody conjugated with horseradish peroxidase. Western blot was developed using Immobilon ${ }^{\text {TM }}$ Western Horseradish Peroxidase Substrate Luminal Reagent (Millipore) and visualized using a Chemiluminescence Imaging System (Clinx Science Instruments, Shanghai, China).

\section{Sulfenic acid modification of wild-type SOD1 in cells}

HEK293T cells overexpressing wild-type SOD1 and its C111S variant with Flag tag transiently were incubated with 0-100 $\mu \mathrm{M} \mathrm{H}_{2} \mathrm{O}_{2}$ at $25^{\circ} \mathrm{C}$ for $2 \mathrm{~h}$, and blocked with $5 \mathrm{mM}$ dimedone. After incubation, the cells were harvested, washed with PBS buffer for three times, and lysed in $200 \mu \mathrm{l}$ ice-cold RIPA buffer with protease inhibitor cocktails. The supernatant was gathered and the protein concentrations of the cellular extracts were determined by BCA assay (Beyotime, Nantong, China). $\alpha$-Flag M2 affinity gel (SigmaAldrich) was used to immunoprecipitate Flag-tagged SOD1. Immunoprecipitation was performed at $4{ }^{\circ} \mathrm{C}$ and in RIPA buffer with protease inhibitor cocktails overnight. The beads were then washed for 3 times with PBS buffer, and the resuspended samples were detected by Western blot using anti-dimedone or anti-FLAG antibodies.

\section{Nano-LC-MS/MS analysis}

The Coomassie Blue-stained gels of $10 \mu \mathrm{M}$ apo wildtype SOD1 treated with $100 \mu \mathrm{M} \mathrm{H} \mathrm{H}_{2} \mathrm{O}_{2}$ for $30 \mathrm{~min}$ and blocked with $5 \mathrm{mM}$ dimedone were scissored out, chopped, trypsinized, and then analyzed with nano-LC-MS/ MS. The tandem mass spectrometric experiments were carried out on a Q Exactive Orbitrap LC-MS/MS System (Thermo Scientific, Waltham, MA). The segmented gradient was 5-8\% Solvent B, $8 \mathrm{~min} ; 8-22 \%$ Solvent B, $50 \mathrm{~min}$; 22-32\% Solvent B, $12 \mathrm{~min}$; 32-95\% Solvent B, $1 \mathrm{~min}$; and $95 \%$ Solvent B, 7 min. The normalized collision energy for HCD and the dynamic exclusion time were $27 \%$ and $40 \mathrm{~s}$, respectively. The protocol for nano-LC-MS/ MS analysis was described in detail previously. ${ }^{70}$

The Coomassie Blue-stained gels of $30 \mu \mathrm{M}$ apo wildtype SOD1 treated with $10.0 \mathrm{mM} \mathrm{H} \mathrm{H}_{2} \mathrm{O}_{2}$ for 30 min were scissored out, chopped, trypsinized, but without reduction/alkylation of cysteines, and then analyzed with nanoLC-MS/MS. The tandem mass spectrometric experiments were carried out on a Q Exactive HF Orbitrap LC-MS/MS System (Thermo Scientific). A $25 \mathrm{~cm}$ Acclaim PepMap C18 column with a 60-min gradient was used to separate the peptides. Q Exactive HF was operated in datadependent acquisition mode with repeated full MS scan $(\mathrm{R}=120 \mathrm{~K}, \mathrm{AGC}=3 \mathrm{e} 6$, maximum injection time $=20$ 
Table 1 Clinical details of patients with ALS and non-ALS at the time when CSF samples were taken

\begin{tabular}{|c|c|c|c|c|}
\hline Case & Gender & Age & Mean age \pm S.D. & Clinical diagnosis \\
\hline \multicolumn{5}{|c|}{ Non-ALS } \\
\hline 1 & M & 52 & $53.5 \pm 4.8$ & Alzheimer disease \\
\hline 2 & M & 50 & & Brainstem infarction \\
\hline 3 & M & 64 & & Intracranial infection \\
\hline 4 & M & 52 & & Type 2 diabetes overlapped by necrotizing myopathy \\
\hline 5 & M & 51 & & Guillain-Barré syndrome \\
\hline 6 & M & 52 & & Cerebral cysticercosis \\
\hline \multicolumn{5}{|c|}{ Sporadic ALS } \\
\hline 1 & M & 56 & $50.3 \pm 6.0$ & Sporadic ALS \\
\hline 2 & M & 49 & & Sporadic ALS \\
\hline 3 & M & 51 & & Sporadic ALS \\
\hline 4 & M & 56 & & Sporadic ALS \\
\hline 5 & M & 63 & & Sporadic ALS overlapped by Dementia with Lewy Bodies \\
\hline 6 & M & 48 & & Sporadic ALS \\
\hline 7 & M & 42 & & Sporadic ALS \\
\hline 8 & $\mathrm{~F}$ & 57 & & Sporadic ALS \\
\hline 9 & M & 47 & & Sporadic ALS \\
\hline 10 & M & 43 & & Sporadic ALS \\
\hline 11 & M & 42 & & Sporadic ALS \\
\hline 12 & M & 45 & & Sporadic ALS \\
\hline 13 & $\mathrm{~F}$ & 50 & & Sporadic ALS \\
\hline 14 & $\mathrm{~F}$ & 49 & & Sporadic ALS \\
\hline 15 & M & 56 & & Sporadic ALS \\
\hline
\end{tabular}

$M$ male, $F$ female

$\mathrm{ms}$, scan range $=300-1800 \mathrm{~m} / \mathrm{z})$ followed by twenty MS/ MS scans $(\mathrm{R}=60 \mathrm{~K}, \mathrm{AGC}=1 \mathrm{e} 6$, maximum injection time $=105 \mathrm{~ms})$. Proteome Discovery version 2.1 and Sequest HT search engine for protein identification were employed to analyze the raw data from Q Exactive HF, against a human SwissProt protein database.

Some important searching parameters were set as following: trypsin was selected as enzyme; the mass tolerance of precursor and the product ions tolerance were $10 \mathrm{ppm}$ and $0.02 \mathrm{Da}$, respectively; dimedone labeling and carbamidomethylation of cysteines were selected as variable modifications for mass spectrometric experiments to detect sulfenic acid modification of SOD1; and dioxidation and trioxidation of cysteine, cysteine oxidation, and deamidation of asparagine and glutamine were selected as variable modifications for mass spectrometric experiments to detect sulfinic/sulfonic acid modification of SOD1.

\section{Annexin V-FITC apoptosis detection assay}

SOD1 stable cells and TDP-43 stable cells were cultured in medium containing $5 \mu \mathrm{M}$ sulfenic acid-modified SOD1 oligomers for 3 days, and then double stained with annexin V-FITC and PI. Olympus FluoView FV1000 laser scanning confocal microscope (Tokyo, Japan) was used to observe apoptotic cells.

Flow cytometry was used to detect apoptotic cells double stained by annexin V-FITC and PI. SOD1 stable cells and TDP-43 stable cells were treated with $10 \mu \mathrm{M}$ sulfenic acid-modified SOD1 oligomers for 3 days to prepare apoptotic cells induced by such SOD1 oligomers. The protocol for flow cytometry analysis was described in detail previously. ${ }^{38}$

\section{Cerebrospinal fluid samples}

The cerebrospinal fluid samples were obtained from

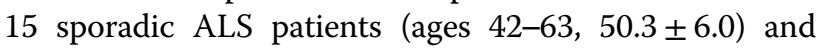


6 age-matched non-ALS control patients (ages 50-64, $53.5 \pm 4.8)$ in the Department of Neurology, Tongji Hospital. See Table 1 for clinical details. The sporadic ALS patients examined in this correspondence were definitely diagnosed $(n=14)$ or probably diagnosed $(n=$ 1 ), and did not have a family history of ALS. The agematched non-ALS control subjects comprised 6 disease controls including patients with Alzheimer disease $(n=$ $1)$, type 2 diabetes overlapped by necrotizing myopathy $(n$ $=1)$, brainstem infarction $(n=1)$, intracranial infection $(n=1)$, Guillain-Barré syndrome $(n=1)$, and cerebral cysticercosis $(n=1)$. Fresh cerebrospinal fluid samples were collected from living sporadic ALS and control cases, and then stored at $-80^{\circ} \mathrm{C}$ until used for immunoprecipitation, Western blot, and ELISA.

\section{Immunoprecipitation (IP) and western blot}

Two hundred microlitre of cerebrospinal fluid samples were mixed with $2 \mu \mathrm{l}$ of a cocktail of protease inhibitors and $2 \mu \mathrm{l}$ of $100 \mathrm{mM}$ dimedone, immunoprecipitated with $1 \mu \mathrm{l}$ of $1.0 \mathrm{mg} / \mathrm{ml}$ rabbit anti-dimedone antibody overnight at $4{ }^{\circ} \mathrm{C}$, and then incubated with $20 \mu \mathrm{l}$ of Protein G Agarose beads for $12-14 \mathrm{~h}$ at $4{ }^{\circ} \mathrm{C}$. The beads were washed thrice with PBS buffer, boiled in SDS-PAGE loading buffer without reducing agents for $5 \mathrm{~min}$, and then probed with Western blot using mouse anti-SOD1 antibody. Another $20 \mu \mathrm{l}$ of CSF samples were boiled in SDS-PAGE loading buffer and then probed with Western blot using rabbit anti-SOD1 antibody and served as the input control. Normalized amount of sulfenic acidmodified SOD1 in CSF samples of 15 patients with sporadic ALS and 6 age-matched non-ALS control patients was calculated by the densitometry of sulfenic acid-modified SOD1 bands divided by that of the total SOD1 bands.

\section{ELISA protocol}

ELISA plates were coated by overnight incubation at $4{ }^{\circ} \mathrm{C}$ with $0.5 \mu \mathrm{g} / \mathrm{ml}$ mouse anti-SOD1 antibody, $100 \mu \mathrm{l} /$ well, diluted in $200 \mathrm{mM} \mathrm{NaHCO}$ buffer (pH 9.6). The plates were washed thrice with PBST buffer, and blocked with $100 \mu \mathrm{l} /$ well of PBST buffer containing 5\% fat-free milk at $37^{\circ} \mathrm{C}$ for $2 \mathrm{~h}$. Hundred microlitre of CSF samples were mixed with $1 \mu \mathrm{l}$ of a cocktail of protease inhibitors and $1 \mu \mathrm{l}$ of $100 \mathrm{mM}$ dimedone, and added into each well of the plates. The ELISA plates were treated with $100 \mu \mathrm{l} /$ well of $0.5 \mu \mathrm{g} / \mathrm{ml}$ rabbit anti-dimedone antibody and then $100 \mu \mathrm{l} /$ well of $1 / 10000$ homologous goat anti-rabbit secondary antibody conjugated with horseradish peroxidase. Two hundred microlitre/well of the substrate $3,3^{\prime}, 5,5^{\prime}$-tetramethylbenzidine was added and the absorbance of the blue product 3,3',5,5'-tetramethyl-4,4'-diphenoquinone was measured with a microplate reader at $630 \mathrm{~nm}$. Statistical analyses were done using $t$-test with three times repeats. Values of $p<0.05$ or $p<0.001$ are considered as statistically significant or much significant.

\section{Ethics statement}

The Institutional Review Board of the College of Life Sciences (CLS), Wuhan University, headed by Dr. BaoLiang Song, authorized all research involving original human work, in accordance with the guidelines for the protection of human subjects. This study was authorized by the ethics committee of CLS, Wuhan University, leaded also by Prof. Song, the Dean of the college.

\section{Acknowledgments}

We sincerely thank Prof. Thomas O'Halloran (Northwestern University) for kindly providing the human SOD1 plasmids and Prof. Chih-chen Wang (Institute of Biophysics, Chinese Academy of Sciences) for her beneficial suggestions. Research of Y.L., W.-C.X., C.L., Z.-X.H., H.-Y.Y., and J.C. is supported by National Key Basic Research Foundation of China Grants 2013 CB910702 and 2012CB911003 to Y.L. National Natural Science Foundation of China Grants 31770833, 31570779, and 31370774 to Y.L., 81271406 to M.Z., and 31571163 to L.W. Fundamental Research Fund for the Central Universities of China 2014204020202 to W.-C.X., and Youth Innovation Promotion Association CAS to L.W.

\section{Author details}

'State Key Laboratory of Virology, College of Life Sciences, Wuhan University, Wuhan 430072, China. ${ }^{2}$ National Laboratory of Biomacromolecules, CAS Center for Excellence in Biomacromolecules, Institute of Biophysics, Chinese Academy of Sciences, Beijing 100101, China. ${ }^{3}$ University of Chinese Academy of Sciences, Beijing 100049, China. ${ }^{4}$ Department of Neurology Tongji Hospital, Tongji Medical College, Huazhong University of Science and Technology, Wuhan 430030, China. ${ }^{5}$ College of Chemistry and Molecular Sciences, State Key Laboratory of Virology, Wuhan University, Wuhan 430072, China. ${ }^{6}$ Hubei Key Laboratory of Cell Homeostasis, College of Life Sciences, Wuhan University, Wuhan 430072, China. ${ }^{7}$ State Key Laboratory of Bioreactor Engineering, School of Pharmacy, East China University of Science and Technology, Shanghai 200237, China

\section{Author contributions}

YL designed research; W-CX, J-ZL, CL, Z-XH, H-YY, B-YH, X-LL and BT performed experiments; JC, D-WP, H-ND, YY and MZ contributed new reagents/analytic tools; W-CX, J-ZL, CL, LW and YL analyzed data; YL, W-CX, CL and LW wrote the paper.

\section{Competing interests}

The authors declare that they have no competing financial interests

\section{Publisher's note}

Springer Nature remains neutral with regard to jurisdictional claims in published maps and institutional affiliations.

\section{Supplementary information}

The online version of this article (https://doi.org/10.1038/s41419-017-0106-4) contains supplementary material.

Received: 3 August 2017 Revised: 23 October 2017 Accepted: 24 October 2017

Published online: 22 January 2018

\footnotetext{
References

1. Polymenidou, M. \& Cleveland, D. W. The seeds of neurodegeneration: prionlike spreading in ALS. Cell 147, 498-508 (2011).
} 
2. Guo, W. et al. An ALS-associated mutation affecting TDP-43 enhances protein aggregation, fibril formation and neurotoxicity. Nat. Struct. Mol. Biol. 18 822-830 (2011).

3. Chattopadhyay, $M$. et al. Initiation and elongation in fibrillation of ALS-linked superoxide dismutase. Proc. Natl Acad. Sci. USA 105, 18663-18668 (2008)

4. Ivanova, M. I. et al. Aggregation-triggering segments of SOD1 fibril formation support a common pathway for familial and sporadic ALS. Proc. Natl Acad. Sci. USA 111, 197-201 (2014).

5. Lang, L. et al. SOD1 aggregation in ALS mice shows simplistic test tube behavior. Proc. Natl Acad. Sci. USA 112, 9878-9883 (2015).

6. Ayers, J. I., Fromholt, S. E., O'Neal, V. M., Diamond, J. H. \& Borchelt, D. R. Prionlike propagation of mutant SOD1 misfolding and motor neuron disease spread along neuroanatomical pathways. Acta Neuropathol. 131, 103-114 (2016).

7. Pokrishevsky, E., Grad, L. I. \& Cashman, N. R. TDP-43 or FUS-induced misfolded human wild-type SOD1 can propagate intercellularly in a prion-like fashion. Sci. Rep. 6, 22155 (2016).

8. Williams, K. L. et al. CCNF mutations in amyotrophic lateral sclerosis and frontotemporal dementia. Nat. Commun. 7, 11253 (2016)

9. Fridovich, I. Superoxide radical and superoxide dismutases. Annu. Rev. Biochem. 64, 97-112 (1995).

10. Nonaka, T. et al. Prion-like properties of pathological TDP-43 aggregates from diseased brains. Cell Rep. 4, 124-134 (2013).

11. Cohen, T. J. et al. An acetylation switch controls TDP-43 function and aggregation propensity. Nat. Commun. 6, 5845 (2015).

12. BosCo, D. A. et al. Wild-type and mutant SOD1 share an aberrant conformation and a common pathogenic pathway in ALS. Nat. Neurosci. 13, 1396-1403 (2010).

13. Zhang, $\mathrm{K}$. et al. The C9orf72 repeat expansion disrupts nucleocytoplasmic transport. Nature 525, 56-61 (2015).

14. Furukawa, Y., Kaneko, K., Yamanaka, K., O'Halloran, T. V. \& Nukina, N. Complete loss of post-translational modifications triggers fibrillar aggregation of SOD1 in the familial form of amyotrophic lateral sclerosis. J. Biol. Chem. 283, 24167-24176 (2008)

15. Münch, C., O'Brien, J. \& Bertolotti, A. Prion-like propagation of mutant superoxide dismutase-1 misfolding in neuronal cells. Proc. Natl Acad. Sci. USA 108, 3548-3553 (2011).

16. Grad, L. I. et al. Intermolecular transmission of superoxide dismutase 1 misfolding in living cells. Proc. Natl Acad. Sci. USA 108, 16398-16403 (2011).

17. Guareschi, S. et al. An over-oxidized form of superoxide dismutase found in sporadic amyotrophic lateral sclerosis with bulbar onset shares a toxic mechanism with mutant SOD1. Proc. Natl Acad. Sci. USA 109, 5074-5079 (2012).

18. Cohen, T. J., Hwang, A. W., Unger, T., Trojanowski, J. Q. \& Lee, V. M. Redox signalling directly regulates TDP-43 via cysteine oxidation and disulphide cross-linking. EMBO J. 31, 1241-1252 (2012).

19. Pokrishevsky, E. et al. Aberrant localization of FUS and TDP43 is associated with misfolding of SOD1 in amyotrophic lateral sclerosis. PLOS ONE 7, e35050 (2012).

20. Jiang, L. L. et al. Structural transformation of the amyloidogenic core region of TDP-43 protein initiates its aggregation and cytoplasmic inclusion. J. Biol. Chem. 288, 19614-19624 (2013).

21. Robinson, J. L. et al. TDP-43 skeins show properties of amyloid in a subset of ALS cases. Acta Neuropathol. 125, 121-131 (2013).

22. Chan, P. K. et al. Structural similarity of wild-type and ALS-mutant superoxide dismutase-1 fibrils using limited proteolysis and atomic force microscopy. Proc. Natl Acad. Sci. USA 110, 10934-10939 (2013).

23. Grad, L. I. et al. Intercellular propagated misfolding of wild-type Cu/Zn superoxide dismutase occurs via exosome-dependent and -independent mechanisms. Proc. Natl Acad. Sci. USA 111, 3620-3625 (2014).

24. Chattopadhyay, M. et al. The disulfide bond, but not zinc or dimerization, controls initiation and seeded growth in amyotrophic lateral sclerosis-linked Cu,Zn superoxide dismutase (SOD1) fibrillation. J. Biol. Chem. 290, 30624-30636 (2015).

25. Shimonaka, S., Nonaka, T., Suzuki, G., Hisanaga, S. \& Hasegawa, M. Templated aggregation of TAR DNA-binding protein of $43 \mathrm{kDa}$ (TDP-43) by seeding with TDP-43 peptide fibrils. J. Biol. Chem. 291, 8896-8907 (2016).
26. Juarez, J. C. et al. Superoxide dismutase 1 (SOD1) is essential for $\mathrm{H}_{2} \mathrm{O}_{2}$-mediated oxidation and inactivation of phosphatases in growth factor signaling. Proc. Natl Acad. Sci. USA 105, 7147-7152 (2008).

27. Rotunno, M. S. \& Bosco, D. A. An emerging role for misfolded wild-type SOD1 in sporadic ALS pathogenesis. Front. Cell. Neurosci. 7, 253 (2013).

28. Gulden, M., Jess, A., Kammann, J., Maser, E. \& Seibert, H. Cytotoxic potency of $\mathrm{H}_{2} \mathrm{O}_{2}$ in cell cultures: impact of cell concentration and exposure time. Free. Radic. Biol. Med. 49, 1298-1305 (2010).

29. Ayala, V. et al. Cell stress induces TDP-43 pathological changes associated with ERK1/2 dysfunction: implications in ALS. Acta Neuropathol. 122, 259-270 (2011).

30. Mulligan, V. K. et al. Early steps in oxidation-induced SOD1 misfolding: implications for non-amyloid protein aggregation in familial ALS. J. Mol. Biol. 421 631-652 (2012).

31. Fujiwara, N. et al. Oxidative modification to cysteine sulfonic acid of Cys111 in human copper-zinc superoxide dismutase. J. Biol. Chem. 282, 35933-35944 (2007).

32. Ezzi, S. A., Urushitani, M. \& Julien, J. P. Wild-type superoxide dismutase acquires binding and toxic properties of ALS-linked mutant forms through oxidation. J. Neurochem. 102, 170-178 (2007).

33. Mo, Z. Y. et al. Low micromolar zinc accelerates the fibrillization of human Tau via bridging of Cys-291 and Cys-322. J. Biol. Chem. 284, 34648-34657 (2009).

34. Zhou, Z. et al. Crowded cell-like environment accelerates the nucleation step of amyloidogenic protein misfolding. J. Biol. Chem. 284, 30148-30158 (2009).

35. Zhu, H. L. et al. Quantitative characterization of heparin binding to Tau protein implication for inducer-mediated Tau filament formation. J. Biol. Chem. 285, 3592-3599 (2010)

36. Svensson, A. K., Bilsel, O., Kondrashkina, E., Zitzewitz, J. A. \& Matthews, C. R. Mapping the folding free energy surface for metal-free human $\mathrm{Cu}, \mathrm{Zn}$ superoxide dismutase. J. Mol. Biol. 364, 1084-1102 (2006).

37. Liu, X. L. et al. Sequence-dependent abnormal aggregation of human Tau fragment in an inducible cell model. BBA-Mol. Basis Dis. 1852, 1561-1573 (2015).

38. Hu, J. Y. et al. Pathological concentration of zinc dramatically accelerates abnormal aggregation of full-length human Tau and thereby significantly increases Tau toxicity in neuronal cells. BBA-Mol. Basis Dis. 1863, 414-427 (2017).

39. Eichner, T. \& Radford, S. E. A diversity of assembly mechanisms of a generic amyloid fold. Mol. Cell. 43, 8-18 (2011).

40. Zeineddine, R. et al. SOD1 protein aggregates stimulate macropinocytosis in neurons to facilitate their propagation. Mol. Neurodegener. 10, 57 (2015).

41. Riccardi, C. \& Nicoletti, I. Analysis of apoptosis by propidium iodide staining and flow cytometry. Nat. Protoc. 1, 1458-1461 (2006).

42. Vermes, I., Haanen, C., Steffens-Nakken, H. \& Reutelingsperger, C. A novel assay for apoptosis. Flow cytometric detection of phosphatidylserine expression on early apoptotic cells using fluorescein labelled annexin V. J. Immunol. Methods. 184, 39-51 (1995).

43. Magrì, A. et al. Overexpression of human SOD1 in VDAC1-less yeast restores mitochondrial functionality modulating beta-barrel outer membrane protein genes. BBA-Biomembranes 1857, 789-798 (2016).

44. Sohal, R. S. \& Weindruch, R. Oxidative stress, caloric restriction, and aging Science 273, 59-63 (1996).

45. Rakhit, R. et al. Oxidation-induced misfolding and aggregation of superoxide dismutase and its implications for amyotrophic lateral sclerosis. J. Biol. Chem. 277, 47551-47556 (2002).

46. Rakhit, R. et al. An immunological epitope selective for pathological monomer-misfolded SOD1 in ALS. Nat. Med. 13, 754-759 (2007).

47. Amri, F., Ghouili, I., Amri, M., Carrier, A. \& Masmoudi-Kouki, O. Neuroglobin protects astroglial cells from hydrogen peroxide-induced oxidative stress and apoptotic cell death. J. Neurochem. 140, 151-169 (2017).

48. Giordana, M. T. et al. TDP-43 redistribution is an early event in sporadic amyotrophic lateral sclerosis. Brain Pathol. 20, 351-360 (2010).

49. Sangwan, S. et al. Atomic structure of a toxic, oligomeric segment of SOD1 linked to amyotrophic lateral sclerosis (ALS). Proc. Natl Acad. Sci. USA 114, 8770-8775 (2017)

50. Furukawa, Y. \& O'Halloran, T. V. Posttranslational modifications in Cu,Znsuperoxide dismutase and mutations associated with amyotrophic lateral sclerosis. Antioxid. Redox. Signal. 8, 847-867 (2006).

51. Collins, M. A., An, J., Hood, B. L., Conrads, T. P. \& Bowser, R. P. Label-free LC-MS/ MS proteomic analysis of cerebrospinal fluid identifies protein/pathway 
alterations and candidate biomarkers for amyotrophic lateral sclerosis. J. Proteome Res. 14, 4486-4501 (2015).

52. Winer, L. et al. SOD1 in cerebral spinal fluid as a pharmacodynamic marker for antisense oligonucleotide therapy. JAMA Neurol. 70, 201-207 (2013).

53. Kasai, T. et al. Increased TDP-43 protein in cerebrospinal fluid of patients with amyotrophic lateral sclerosis. Acta Neuropathol. 117, 55-62 (2009).

54. Bourbouli, M. et al. Cerebrospinal fluid TAR DNA-Binding protein 43 combined with Tau proteins as a candidate biomarker for amyotrophic lateral sclerosis and frontotemporal dementia spectrum disorders. Dement. Geriatr. Cogn. Disord. 44, 144-152 (2017)

55. Zetterström, P., Andersen, P. M., Brännström, T. \& Marklund, S. L. Misfolded superoxide dismutase-1 in CSF from amyotrophic lateral sclerosis patients. J. Neurochem. 117, 91-99 (2011).

56. Da Cruz, S. et al Misfolded SOD1 is not a primary component of sporadic ALS Acta Neuropathol. 134, 97-111 (2017).

57. Gaiani, A. et al. Diagnostic and prognostic biomarkers in amyotrophic lateral sclerosis: neurofilament light chain levels in definite subtypes of disease. JAMA Neurol. 74, 525-532 (2017).

58. Gendron, T. F. et al. Phosphorylated neurofilament heavy chain: A biomarker of survival for C9ORF72-associated amyotrophic lateral sclerosis. Ann. Neurol. 82, 139-146 (2017).

59. Lange, D. J. et al. Pyrimethamine significantly lowers cerebrospinal fluid Cu/Zn superoxide dismutase in amyotrophic lateral sclerosis patients with SOD1 mutations. Ann. Neurol. 81, 837-848 (2017).

60. Parge, H. E., Hallewell, R. A. \& Tainer, J. A. Atomic structures of wild-type and thermostable mutant recombinant human $\mathrm{Cu}, \mathrm{Zn}$ superoxide dismutase. Proc. Natl Acad. Sci. USA 89, 6109-6113 (1992).
61. Valle, C. \& Carri, M. T. Cysteine modifications in the pathogenesis of ALS. Front Mol. Neurosci. 10, 5 (2017)

62. Cozzolino, M. et al. Cysteine 111 affects aggregation and cytotoxicity of mutant $\mathrm{Cu}, \mathrm{Zn}$-superoxide dismutase associated with familial amyotrophic lateral sclerosis. J. Biol. Chem. 283, 866-874 (2008).

63. Solsona, $C$. et al. Altered thiol chemistry in human amyotrophic latera sclerosis-linked mutants of superoxide dismutase 1. J. Biol. Chem. 289, 26722-26732 (2014).

64. Chen, $X$. et al. Oxidative modification of cysteine 111 promotes disulfide bond-independent aggregation of SOD1. Neurochem. Res. 37, 835-845 (2012).

65. Nagano, S. et al. A cysteine residue affects the conformational state and neuronal toxicity of mutant SOD1 in mice: relevance to the pathogenesis of ALS. Hum. Mol. Genet. 24, 3427-3439 (2015)

66. Álvarez-Zaldiernas, C. et al. Cellular redox systems impact the aggregation of $\mathrm{Cu}, \mathrm{Zn}$ superoxide dismutase linked to familial amyotrophic lateral sclerosis. J. Biol. Chem. 291, 17197-17208 (2016).

67. Israelson, A. et al. Macrophage migration inhibitory factor as a chaperone inhibiting accumulation of misfolded SOD1. Neuron. 86, 218-232 (2015).

68. Li, C. et al. Cupric ions induce the oxidation and trigger the aggregation of human superoxide dismutase 1. PLoS ONE 8, e65287 (2013).

69. Meng, S. R. et al. Fibril-forming motifs are essential and sufficient for the fibrillization of human Tau. PLoS ONE 7, e38903 (2012).

70. Hou, J. et al. Temporal transcriptomic and proteomic landscapes of deteriorating pancreatic islets in type 2 diabetic rats. Diabetes $\mathbf{6 6}$ 2188-2200 (2017). 